\title{
Review and Evaluation of the Effects of Xenobiotic Chemicals on Microorganisms in Soil
}

\author{
R. J. Hicks \\ P. Van Voris
}

February 1988

Prepared for the

U.S. Environmental Protection Agency

under a Related Services Agreement

with the U.S. Department of Energy

Contract DE-AC06-76RLO 1830

Pacific Northwest Laboratory

Operated for the U.S. Department of Energy

by Battelle Memorial Institute 


\title{
DISCLAIMER
}

This report was prepared as an account of work sponsored by an agency of the United States Government. Neither the United States Government nor any agency thereof, nor Battelle Memorial Institute, nor any or their employees, makes any warranty, expressed or implied, or assumes any legal liability or responsibility for the accuracy, completeness, or usefulness of any information, apparatus, product, or process disclosed, or represents that its use would not infringe privately owned rights. Reference herein to any specific commercial product, process, or service by trade name, trademark, manufacturer, or otherwise does not necessarily constitute or imply its endorsement, recommendation, or favoring by the United States Government or any agency thereof, or Battelle Memorial Institute. The views and opinions of authors expressed herein do not necessarily state or reflect those of the United States Government or any agency thereof, or Battelle Memorial Institute.

\author{
PACIFIC NORTHWEST LABORATORY \\ operated by \\ BATTELLE MEMORIAL INSTITUTE \\ for the \\ UNITED STATES DEPARTMENT OF ENERGY \\ under Contract DE-AC06-76RLO 1830
}

\begin{tabular}{|c|c|}
\hline \multicolumn{2}{|c|}{$\begin{array}{l}\text { Printed in the United States of America } \\
\text { Available from } \\
\text { National Technical Information Service } \\
\text { United States Department of Commerce } \\
5285 \text { Port Royal Road } \\
\text { Springfield, Virginia } 22161\end{array}$} \\
\hline \multicolumn{2}{|c|}{$\begin{array}{l}\text { NTIS Price Codes } \\
\text { Microfiche A01 }\end{array}$} \\
\hline \multicolumn{2}{|c|}{ Printed Copy } \\
\hline Pages & $\begin{array}{l}\text { Price } \\
\text { Codes }\end{array}$ \\
\hline 001-025 & $\mathrm{A} 02$ \\
\hline $026-050$ & $\mathrm{~A} 03$ \\
\hline $051-075$ & A04 \\
\hline $076-100$ & A05 \\
\hline $101-125$ & A06 \\
\hline $126-150$ & A07 \\
\hline $151-175$ & $A 0 B$ \\
\hline $176-200$ & $\mathrm{~A} 09$ \\
\hline $201-225$ & A010 \\
\hline $226-250$ & A011 \\
\hline 251.275 & A012 \\
\hline $276-300$ & A013 \\
\hline
\end{tabular}


REVIEW AND EVALUATION OF THE EFFECTS OF XENOBIOTIC CHEMICALS ON

MICROORGANISMS IN SOIL

\author{
R. J. Hicks \\ P. Van Voris
}

February 1988

Dr. Charles Hendricks

EPA Project Office

Prepared for

U.S. Environmental Protection Agency

Corvallis Environmental Research Laboratory

Corvallis, Oregon 97333

under a Related Services Agreement

with the U.S. Department of Energy

Contract DE-AC06-76RLO 1830

Pacific Northwest Laboratory

Richland, Washington 99352 


\section{DISCLAIMER}

The information in this document has been funded wholly or in part by the United States Environmental Protection Agency under Interagency Agreement DW89931928894-01-0 to Pacific Northwest Laboratory, operated for the U.S. Department of Energy by Battelle Memorial Institute. It has been subject to the Agency's peer and administration review, and it has been approved for publication as an EPA document. 


\section{EXECUTTVE SUMMARY}

The primary objective of this document was to review and evaluate the relevance and quality of existing xenobiotic data bases and test methods for evaluating: 1) direct and indirect effects (both adverse and beneficial) of xenobiotics on the soil microbial community; 2) direct and indirect effects of the soil microbial community on xenobiotics; and 3) adequacy of test methods used to evaluate these effects and interactions. Xenobiotic chemicals are defined here as those compounds, both organic and inorganic, produced by man and introduced into the environment at concentrations that cause undesirable effects. Because soil serves as the inain repository for many of these chemicals, it therefore has a major role in determining their ultimate fate. Once released, the distribution of xenobiotics between environmental compartments depends on the chemodynamic properties of the compounds, the physicochemical properties of the soils, and the transfer between soil-water and soil-air interfaces and across biological membranes. Abiotic and biotic processes can transform the chemical compound, thus altering its chemical state and, subsequently, its toxicity and reactivity. Ideally, the conversion is to carbon dioxide, water, and mineral elements, or, at least, to some harmless substance. However, intermediate transformation products, which can become toxic pollutants in their own right, can sometimes be formed.

When exposed to xenobiotic compounds, various segments of the soil nicrobial community are affected to different extents. The degree to which a xenobiotic affects microbial activities is largely dependent on the chemical, its dosage, and the particular physicochemical parameters of the environment, such as soil type, temperature, water content, $\mathrm{pH}$, method of application, and other factors. Soil physicochemical factors are particularly important and probably account for the variations in toxic effects often seen with the same compound. A strong correlation between compound class and its effects on soil microorganisms cannot be established because of a paucity of data on the effects of organic compounds other than pesticides. However, a few generalizations have emerged. Broad-range biocidal compounds, such as soil fumigants, appear to affect detrimentally all microbial processes, at least temporarily. This effect is also observed 
with most heavy metals. Compounds such as herbicides and insecticides are less detrimental to microbial activity and, under certain conditions, may stimulate activity.

Some soil microbial processes and properties appear to be more sensitive to xenobiotics than others. For example, nitrification appears to be highly sensitive, whereas nitrogen mineralization is relatively resistant to xenobiotics. These results reflect the differences in the diversity of microorganisms mediating these processes.

The present state of knowledge of the cytological and biochemical effects of xenobiotics does not provide any definitive evidence regarding their mode of action. However, available data suggest that xenobiotics may interfere with photosynthesis, oxidative metabolism, and the synthesis of cellular constituents. In addition, certain compounds, such as the chlorinated aromatics, do alter the composition of the cellular membrane, thereby changing cell membrane permeability and altering cellular physiology.

Numerous methods exist for measuring different microbial processes, microbial populations, and soil enzymes, and most of these methods can be applied to assess the effects of xenobiotics. However, one of the major research needs is to establish which of the available methods are the most valid for investigating particular classes of xenobiotic compounds. Additional studies are also needed to identify and select the microbially mediated ecological processes that can best be used to generate meaningful data of the short- and long-term effects of xenobiotics before selection and standardization of techniques can be accomplished. Finally, a systemic examination of those classes of xenobiotics that have not been evaluated for their effects on microorganisms needs to be performed to allow development of a predictive model for environmental risk assessment. 


\section{CONTENTS}

EXECUTIVE SUMMARY ......................................................................... iii

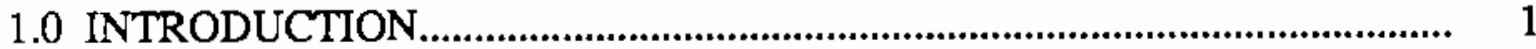

2.0 SOIL AS A MICROBIAL HABITAT.....................................................

2.1 SOLID PHASE ..................................................................................

2.2 WATER PHASE ............................................................................. 7

2.3 GASEOUS PHASE ........................................................................ 8

3.0 MICROORGANISMS AND THEIR ACTIVITIES IN SOIL ......................... 9

3.1 ABUNDANCE AND TYPE ............................................................... 9

3.2 ACTIVITTES IN SOIL .................................................................. 13

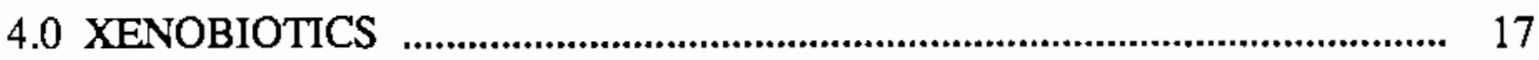

4.1 CLASSIFICATION AND SOURCES ….............................................. 17

4.2 INTERACTIONS OF XENOBIOTICS WITH SOILS …………........... 22

5.0 ENVIRONMENTAL FACTORS THAT INFLUENCE INTERACTIONS

BETWEEN MICROORGANISMS AND XENOBIOTICS …...................... 27

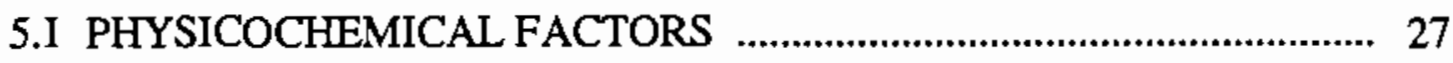

6.0 EFFECTS OF XENOBIOTICS ON MICROORGANISMS IN SOIL ............. 33

6.1 MICROBIOLOGICAL PROCESSES ..................................................... 33

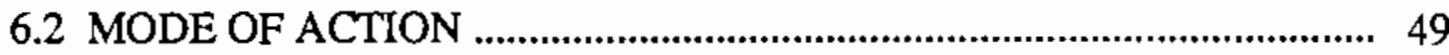

7.0 METHODS OF ASSESSING THE EFFECTS OF XENOBIOTICS ON

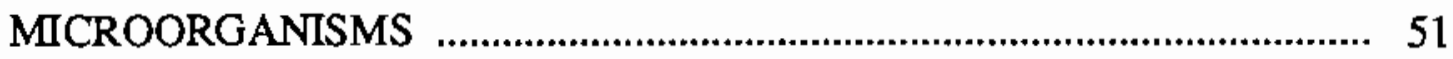

7.1 LABORATORY TEST SYSTEMS …….......................................... 52

7.2 METHODS FOR ASSESSING XENOBIOTIC IMPACTS ON RELEVANT MICROBIAL PROCESSES AND PROPERTIES .............. 55

7.3 ASSESSING THE EFFICACY OF TEST METHODS ........................... 60

8.0 CONCLUSIONS AND RECOMMENDATIONS …..................................... 65

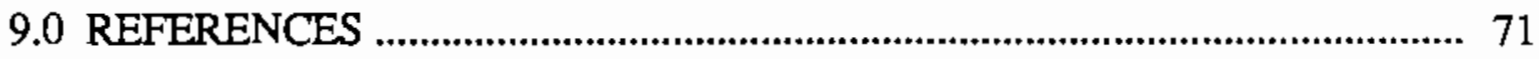





\section{EIGURES}

3.1 The Carbon Cycle .................................................................................... 14

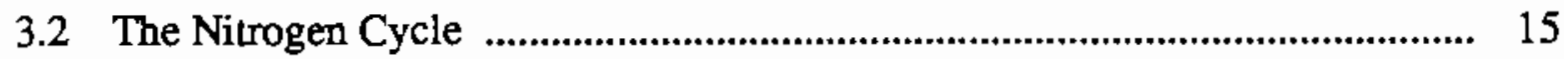

4.1 Percentage of Hazardous Substances Generated by Standard

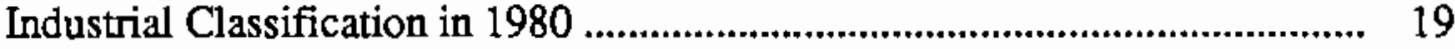

4.2 Interactions of Xenobiotic Chemicals with Soils ......................................... 22

6.1 Inhibition of Soil-Nitrifying Bacteria by Degradation Products of Diuron and Propanil

7.1 Terrestrial Soil-Core Microcosm Test System ................................................. 53 


\section{TABLES}

3.1 Relative Proportion of Bacterial Genera Commonly Found in Soils ............. 10

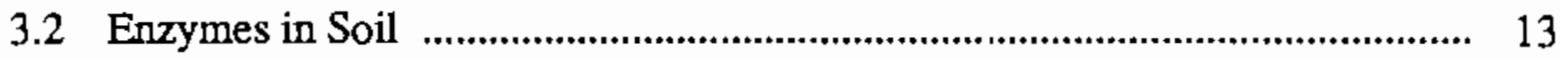

4.1 Examples of Important Xenobiotic Compounds ........................................... 18

4.2 Classification of Herbicides Based on Chemical Group and Class ................ 20

4.3 Chemical Classification of Fossil Fuel-Related Organic Residues ................ 21

4.4 Processes in Soil That Affect the Behavior of Xenobiotics ............................. 23

4.5 Influence of Structure on Biodegradability of Xenobiotics.............................. 24

6.1 Variations in the Effects of Selected Xenobiotics on Soil Respiration ............ 35

6.2 Effects of Selected Xenobiotics on Soil Enzymatic Activity ......................... 44

6.3 Effects of Selected Xenobiotics on Soil Microbial Populations ..................... 45

7.1 Evaluation of Major Test Systems for Measuring the Effects of Xenobiotics on Soil Microorganisms 


\subsection{INTRQDUCTION}

Xenobiotics are defined here as both organic and inorganic anthropogenic compounds that are introduced into the environment at concentrations that cause undesirable effects. Some of these compounds may be purposefully released and are designed to be beneficial to man (e.g., pesticides). Alternatively, they may be accidentally released into the environment as wastes or residues from industrial manufacturing and processing of fossil fuels. These compounds may interact at a number of differing trophic levels within an ecosystem. To estimate the environmental risks to the soil ecosystem associated with release, either purposeful or accidental, of xenobiotics, two questions were posed: first, are there sufficient data in the literature to assess accurately the significance of the impacts of xenobiotics on the microbiological portion of the soil system; and second, are the experimental approaches used in assessing those effects adequate, or are new or improved methods needed? Because of limitations in scope and budget, effort was focused only on the microbiological component of the soil system. The principal objective of this assessment was to review and evaluate the relevance and quality of existing data bases on the effects of xenobiotics on soil microorganisms and determine the adequacy of test methods relating to the following:

\section{1. direct and indirect effects (both beneficial and adverse) of xenobiotics on the soil microbial community}

2. direct and indirect effects of the soil microbial community on xenobiotics

\section{3. adequacy of test methods used to evaluate these effects and interactions.}

This effort has produced a series of conclusions regarding the quality and breadth of published data on xenobiotics in soil systems and the suitability of current methods used to measure any potential impacts. On the basis of these conclusions, areas that need additional research have been identified. 


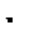

. 


\subsection{SOIL AS A MICROBIAL HABITAT}

Soil is one of the most dynamic sites of biological interactions in nature, serving as a growth medium for vegetation and as a habitat for fauna. In addition, soil serves as a receptacle for the multitude of organic and inorganic chemicals released by man, either intentionally, as in the case of agricultural chemicals, or accidentally, and thus has a major role in determining the overall quality of our environment. The soil environment is dominated by a solid phase composed of inorganic minerals; plant animal, and microbial residues in various stages of decay; and a living and metabolizing microbiota (Stotzky 1986). The solid phase is surrounded by fluctuating aqueous and gaseous phases. The proportion and physicochemical properties of these three phases strongly influence the growth, activity, and population dynamics of microorganisms in soil and also modify the effects of xenobiotics on the microbial community. Therefore, it is important to review briefly the nature and properties of soils before describing the effects of xenobiotics on microorganisms in soil.

\subsection{SQLID PHASE}

Soil solids are composed of mineral material, such as sand, silt, and clay particles, and of organic matter, consisting of living and dead biomass. The proportion of each component in a particular soil controls its physical and chemical properties, such as porosity, water-holding capacity, cation-exchange capacity, cation- to anion-exchange ratio, and aggregate stability. In terms of the behavior of xenobiotics in soil and their effects on indigenous microbial populations, the most influential soil components appear to be the colloid-sized clay minerals and organic particles (Stotzky and Burns 1982). This influence results, in part, from their high surface-to-volume ratios, their ionic properties, and their high affinity for water molecules (Burns 1983; Stotzky 1986). Consequently, xenobiotics, as well as microorganisms, tend to concentrate at colloid-water interfaces. In addition to clays and organic matter, microorganisms are also a component of soil solids that can influence the behavior of xenobiotics. 


\subsubsection{Clays}

The building blocks of clay minerals are two basic units composed of oxygen or hydroxide and silicon or aluminum. One unit is the silicon tetrahedron in which oxygen atoms form the comers of a tetrahedron held together by a silicon ion in the center. It is possible for isomorphic substitutions (i.e., substitution by an ion of similar size but a lower valence with essentially no modification in crystalline structure) to occur between the tetravalent silicon ion and trivalent ions, such as aluminum, resulting in a net negative charge. The other unit is the aluminum octahedron in which six hydroxyl groups or oxygen atoms form the comer of an octahedron held together by an aluminum ion in the center. As in the silicon tetrahedron, isomorphic substitutions between the trivalent aluminum atom and divalent ions, such as magnesium or ferrous iron atoms, can occur, creating a negative charge within the unit. Each of these basic units (e.g., silica tetrahedron or aluminum octahedron) can link together horizontally to form sheets commonly referred to as tetrahedral or octahedral sheets, respectively.

Clay minerals consist of silicon tetrahedral and aluminum octahedral sheets held together by shared oxygen atoms. The minerals consist of two main types of unit layers, depending on the ratio of tetrahedral to octahedral sheets, whether $1: 1$ (Si-Al) or 2:1 (Si-Al-Si). The physical and chemical properties of a particular clay mineral depend on the ratio of tetrahedral to octahedral sheets and on the nature and location of the isomorphic substitutions that occur within the crystalline structure.

Isomorphic substitutions within the basic unit impart a net negative charge to most clay minerals. In 2:1 type clays, isomorphic substitution accounts for the majority of the negative charges. In 1:1 clays, there is little isomorphic substitution, and unsatisfied charges resulting from broken edges on the clay are primarily responsible for the negative charges. The negative charges are compensated by exchangeable cations (e.g., $\left.\mathrm{Al}^{+3}, \mathrm{Fe}^{+3}, \mathrm{Ca}^{+2}, \mathrm{Mg}^{+2}, \mathrm{~K}^{+}, \mathrm{Na}^{+}, \mathrm{H}^{+}, \mathrm{NH}_{4}^{+}\right)$in the ambient soil solution. The amount of charge-neutralizing cations that can be retained by clays is termed the cation-exchange capacity (CEC) and is expressed in units of milliequivilents of cations a clay can adsorb per unit weight. 
Clay minerals differ in the position (whether mainly in the tetrahedral or octahedral sheet) and amount of isomorphic substitution (e.g., density of charge) occurring within the lattice structure, as well as in the type and amount of hydration of charge-compensating cations. These variables influence the amount and degree of interlayer associations that occur, which, in turn, influence the degree of expansion a clay undergoes on wetting. Some 2:1 type clays such as montmorillinite expand considerably on wetting, resulting in a large surface area that can serve as a site of adsorption for inorganic and organic molecules. Other 2:1 clays, such as illite, as well as 1:1 clays, do not normally expand on wetting and consequently have a lower surface-to-volume ratio. Some 2:1 clays, such as vermiculite, exhibit limited expansion. The increased surface area of expanding clays coupled with the high amount of isomorphic substitution that often occurs in these types of clays usually results in higher CEC and greater adsorption of water and gases on these clays than in the nonexpanding types. Certain clays that often exhibit positive charge sites at lower $\mathrm{pH}$ values can participate in the adsorption of anions from solution. These positive charge sites primarily originate from broken bonds in the octahedral sheet that expose $\mathrm{Al}^{+3}$ groups on the edges of the clay mineral.

The preceding section is not intended to be an exhaustive review on clays, but rather a brief summary of some of the physical and chemical properties of clay minerals that may have a role in determining the effect of xenobiotics on microorganisms in soil. For more detailed reviews of the aforementioned material the reader is referred to the excellent works of Baver et al. (1972), Dixon and Weed (1977), or Russell (1973).

\subsubsection{Organic Matter}

Soil organic matter includes a broad spectrum of organic constituents that can be divided into two major types: 1) nonhumic substances, consisting of essentially unaltered plant, animal, and microbial debris and of compounds belonging to the well-known classes of organic chemistry (e.g., aliphatic and aromatic acids, amino acids, carbohydrates, fats, and waxes); and 2) humic substances, a series of high molecular weight, dark-colored substances formed by secondary synthesis reactions, many of which are mediated by microbes (Stevenson 1985). Humic substances rank with colloidal clays in terms of importance to microbial activity and xenobiotic behavior. 
A variety of functional groups, including $\mathrm{COOH}$, phenolic $\mathrm{OH}$, enolic $\mathrm{OH}$, alcoholic $\mathrm{OH}$, quinone, amine, hydroxyquinone, and lactone, are found in humic substances (Stevenson 1985). The $\mathrm{pK}_{\mathrm{a}}$ values of most of the functional groups are such that soil organic colloids are predominately negatively charged in most soils and, therefore, contribute to the CEC of the soil. However, positively charged sites are often found on soil organic matter, particularly at low $\mathrm{pH}$. Thus, as with clays, soil organic matter can also have an associated anion-exchange capacity (AEC). There is little information on the importance of the AEC of organic colloids or clays to the behavior of xenobiotics or microorganisms in soils. The AEC of organic colloids and clays is often overshadowed by their CEC; however, as most xenobiotics and microorganisms are net negatively charged, the AEC of organic and inorganic colloids may be important in the interactions of these colloids with xenobiotics and inicrobes.

In addition to their ionic nature, humic substances have a number of other properties that are important in the behavior of xenobiotics. Humic substances are polydisperse materials that expand on wetting and therefore have extensive internal surface area (Stotzky and Burns 1982). The large surface area coupled with the large number of functional groups make humic colloids important in the adsorption of xenobiotics in soils through such mechanisms as H-bonding and van der Waals forces. Organic colloids also contain hydrophobic sites that are important in the adsorption of nonpolar organic compounds.

A more detailed description of the types and activities of microorganisms in soil is deferred to a later section; however, it is important to include microbes in this section because they do contribute to the solid phase of soil. The surfaces of microorganisms are predominantly negatively charged (Bums 1979); however, as with organic colloids, positively charged sites can occur. Therefore, the possibility exists for the adsorption of both anionic and cationic xenobiotics to living organisms. In addition, portions of the outer surfaces of many microorganisms are hydrophobic and, thus, may contribute to the binding of nonpolar xenobiotics. 


\subsection{WATER PHASE}

The variable amount and the energy state of water in soil are important factors that affect the growth of microorganisms in soil and also, because of the solvent properties of water, the behavior of xenobiotics. Soil water governs the air content and gas exchange in soil, thus affecting the activity of microorganisms and the chemical state of the soil (e.g., redox potential). In addition, soil water content affects the swelling of clays and, thus, the specific surface area of soils available for interaction with xenobiotics.

The amount of water contained in a unit mass or volume of soil can be characterized in terms of water content. The physicochemical condition or state of soil water is characterized in terms of its free energy or potential. Water potential is the free energy of water in a system, relative to the free energy of a reference pool of pure, free water (Papendick and Campbell 1980). The availability of water (e.g., activity of water) for physiological processes decreases as the water potential decreases.

In soils, sand- and silt-sized particles do not retain water against gravitational pull; therefore, it is primarily the clay fraction that retains enough water to sustain microbial growth (Stotzky 1986). Stotzky (1986) has speculated that this is the reason for the apparent correlation of microbial activity with the clay fraction. Soil organic matter also retains water; however, little is known about the importance of organic matter-associated water to microbial events in soils.

Water adjacent to the surface of clays is presumed to be highly ordered because of charge interactions between the water, the clay surface, and cations associated with the surface (Russell 1973; Low 1961, 1979; Farmer 1978). This ordering of water lowers the activity of water so that it is probably unavailable to microorganisms. Therefore, it is likely that microorganisms are growing some distance from the clay surface in the region where water is still under the attraction of the clays but where its activity is high enough to support microbial growth (Stotzky 1986). It is probable that xenobiotics would also be concentrated in this region (Stotzky 1986). Additional information is needed about 
the effects of the physicochemical characteristics of soil water on the interactions among water, microorganisms, and xenobiotics in soils.

\subsection{GASEOUS PHASE}

The soil pores that are not filled with water contain gases that constitute the soil atmosphere. Plant roots and organisms living in the soil remove $\mathrm{O}_{2}$ from the soil atmosphere and respire $\mathrm{CO}_{2}$ into it; therefore, the composition of the atmosphere within the soil pores usually differs from that of the atmosphere above the soil in being richer in $\mathrm{CO}_{2}$ and poorer in $\mathrm{O}_{2}$. The magnitude of this difference depends on the rate of removal of $\mathrm{O}_{2}$ and the rate of gas exchange between the atmosphere and the soil pores.

In well-aerated soils, the rate of $\mathrm{O}_{2}$ transfer from the atmosphere is nearly equal to the rate of its removal by organisms. Under these conditions, the dominant metabolic activities occurring in soil are those in which $\mathrm{O}_{2}$ is used as the terminal electron acceptor and as a substrate for oxygenase enzymes. However, even in well-aerated soils, and particularly in poorly aerated soils, microsites can occur within the soil wherein $\mathrm{O}_{2}$ consumption exceeds $\mathrm{O}_{2}$ replacement. The $\mathrm{O}_{2}$ concentration can then fall nearly to zero, and prolonged anaerobic conditions can result in metabolic activities dominated by reduction reactions such as fermentation, denitrification, sulfate reduction, and methane formation. In $\mathrm{O}_{2}$-deficient soils, other gases, including aldehydes, alcohols, and ethylene, $\mathrm{N}_{2} \mathrm{O}$ and $\mathrm{N}_{2}$ from denitrification, $\mathrm{CH}_{4}$ from methanogenesis, and $\mathrm{H}_{2} \mathrm{~S}$ from anaerobic sulfate reduction, can occur in high concentrations in the soil atmosphere (Stotzky and Schenck 1976). 


\subsection{MICROORGANISMS AND THEIR ACTIVITIES IN SOIL}

The soil biota consists of microscopic and macroscopic inhabitants that interact as a distinct biological community. Microscopic inhabitants include bacteria, fungi, algae, and protozoa, and macroscopic communities include nematodes, oligochaetes (earthworms), arthropods (micro and macro), and gastropods (snails). Although all these organisms have an important role in the global cycling of nutrients, the microscopic inhabitants (particularly the bacteria and fungi) of soil have a unique role because of their metabolic diversity (Alexander 1977). Therefore, this section focuses on these populations.

\subsection{ABUNDANCE AND TYPES}

A diverse range of microorganisms exists in soils. Numbers of microorganisms in soil habitats are normally higher than in other habitats, such as freshwater or marine environments.

\subsubsection{Bacteria}

The numbers of bacteria occurring in soils are usually higher than those of the other groups; however, because of their small size in relation to the large cell size and extensive filaments of the other groups, bacteria account for less than half of the total microbial biomass in soil (Alexander 1977). Typically, there are between $10^{6}$ and $10^{9}$ bacteria per gram of soil. In well-aerated soils, both bacteria and fungi are present; however, if $\mathrm{O}_{2}$-limited conditions are present, bacteria account for most of the microbial community biomass.

Common bacterial genera found in soils include Acinetobacter, Agrobacterium, Alcaligenes, Arthrobacter, Bacillus, Brevibacterium, Caulobacter, Cellulomonas, Clostridium, Corynebacterium, Flavobacterium, Micrococcus, Mycobacterium, Pseudomonas, Staphylococcus, Streptococcus, and Xanthomonas (Atlas and Bartha 1987). The relative proportion of individual bacteria varies widely in different soils (Table 3.1). 
Actinomycetes can comprise between $10 \%$ and $33 \%$ of the bacterial population in soil (Alexander 1977). The most common genera include Streptomycetes, Nocardia, Micromonospora, and Actinomyces. Actinomycetes are relatively resistant to adverse conditions, such as desiccation, extremes in $\mathrm{pH}$, and the lack of easily metabolizable carbon sources.

A number of bacteria in soil are plant or animal pathogens. Some pathogenic bacteria are allochthonous and enter the soil in association with diseased plant or animal tissues. Examples of plant pathogens found in soil are Agrobacterium, Corynebacterium, Erwinia, some Pseudomonas, and Xanthomonas; animal pathogens include Klebsiella, Clostridium, Streptococcus, and Salmonella (Atlas and Bartha 1987). Most of these allochthonous organisms are normally unable to compete with saprophytic bacteria and are eliminated through competitive exclusion processes; however, many are nonobligate pathogens or have evolved a permanent soil phase and are able to reproduce and grow.

Table 3.1. Relative Proportion of Bacterial Genera Commonly Found in Soils ${ }^{(a)}$
Genus
Percentage

\begin{tabular}{ll}
\hline & \\
Arthrobacter & $5-60$ \\
Bacillus & $7-67$ \\
Pseudomonas & $3-15$ \\
Agrobacterium & $1-20$ \\
Alcaligenes & $1-20$ \\
Flavobacterium & $2-12$ \\
Corynebacterium & $2-10$ \\
Micrococcus & $<5$ \\
Staphylococcus & $<5$ \\
Xanthomona & $<5$ \\
Mycobacterium & $<5$
\end{tabular}

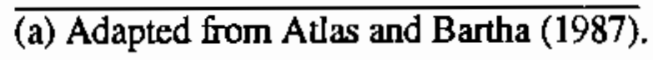


Soil bacteria are particularly significant to, and occupy a key position in, the global cycling of carbon and other elements. Their diverse metabolic capabilities enable them to exploit many sources of energy and cell carbon. Unique metabolic features of bacteria include anaerobic respiration, chemolithotrophic growth, fixation of molecular nitrogen, and utilization of methane (Schlegel and Jannasch 1981). These unique metabolic features render soil bacteria the principal agents for the global cycling of many inorganic compounds, especially nitrogen, sulfur, and phosphorus, but also metals and metalloids such as arsenic, iron, mercury, manganese, and selenium.

\subsubsection{Fungi}

Although numerically much less abundant (between $10^{4}$ and $10^{6}$ fungal propagules per gram soil) than bacteria, fungi are the major contributors to soil biomass and can account for as much as $70 \%$ by weight of the biomass (Lynch 1983). Soil fungi can occur free-living or in mycorrhizal association with plant roots. Members of the class of Fungi Imperfecti such as Aspergillus, Geotrichum, Penicillium, and Trichoderma are the fungi most frequently isolated; however, numerous ascomycetes and basidiomycetes also occur in soil (Atlas and Bartha 1987). The presence of yeast can be demonstrated in most soils, and some species have been isolated exclusively from soils (Alexander 1977; Atlas and Bartha 1987).

Most fungi in soil are opportunistic. They grow and conduct their metabolic activities when environmental conditions (e.g., nutrients, moisture, temperature, aeration) are favorable. Soil fungi are active in the transformation of cellulose and are the principal agents for the transformation of lignins produced by plants. The breakdown of these polymers releases single molecules that are subsequently used by other soil organisms, particularly bacteria.

\subsubsection{Algae and Protozoa}

A number of genera of algae and protozoa live in soil or on the soil surface. Population densities have been estimated to be between $10^{1}$ and $10^{6}$ per gram soil for algae and between $10^{4}$ and $10^{5}$ per gram soil for protozoa (Alexander 1977; Atlas and Bartha 1987). The abiotic environmental parameters most influential in regulating the 
growth of algae and protozoa in soils include sunlight and $\mathrm{CO}_{2}$ for algae and $\mathrm{O}_{2}$ for protozoa. Protozoa are important predators in soil and help to regulate the size of bacterial populations (Alexander 1977). Algae contribute to the organic carbon input of soil and also contribute to soil structure and erosion control (Alexander 1977).

\subsubsection{Root-Associated Microorganisms}

Many microorganisms in soil interact with plant roots on the root surface (rhizoplane) or within the region directly imfluenced by the root (rhizosphere). Microbial populations within the rhizosphere are usually higher in number per unit weight or volume of soil and physiologically different than free-living microorganisms (Atlas and Bartha 1987). These differences have been attributed to the release of substances from roots (root exudates) that modify the soil environment.

The interactions between microorganisms and plants can be mutually beneficial to the plant and its associated microorganisms. For example, the roots of many plants establish a mutualistic relationship with fungi, called mycorrhizal fungi, in which the fungus becomes an integral part of the plant root. The mycorrhizae enhance the uptake of mineral nutrients and enable plants to grow in habitats in which they otherwise would not grow. In return, the fungus obtains organic carbon and possibly other nutrients from the plant host. Other beneficial associations include the symbiosis between nitrogen-fixing bacteria (e.g., Rhizobium) and leguminous plants.

The microbial community of the rhizosphere is composed mainly of nonpathogenic microorganisms; however, plant pathogens do exist in the soil and under certain conditions can invade and form harmful relationships (from the plant's view) with the host plant. Variables that control the relationship between plant pathogenic microorganisms and the host plant include the activity of other soil microorganisms as antagonists to the pathogen, the physiological status of the plant, the presence of protective surfaces on the root, and root exudates (Alexander 1977). 


\subsubsection{Cell-Free Enzymes in Soil}

The overall biochemical activity of soil results from a series of reactions catalyzed by enzymes, either as intracellular components of the microbial community or as extracellular (i.e., cell-free) enzymes. Cell-free enzymes exist in soil as a result of their excretion into the soil by living cells or after the lysis of dead plant or microbial cells. The activity of more than 50 enzymes, some of which are listed in Table 3.2 , has been demonstrated in soil (Lynch 1983).

\subsection{ACTIVITIES IN SOIL}

Soil microorganisms have a primary catabolic role in the environment through degradation of plant and animal residues, which contributes to the cycling of nutrients. The activities of microorganisms in soil are essential to the global cycling of carbon, nitrogen, sulfur, phosphorus, and other elements, because many substances cannot be degraded by organisms other than microbes (Doetsch and Cook 1974).

\begin{tabular}{cl} 
Table 3.2 & Enzymes in Soil (a) \\
\hline Oxidoreductases & \\
& Catalase \\
& Catachol oxidase \\
& Dehydrogenase \\
& Diphenol oxidase \\
& Glucose oxidase \\
& Peroxidase \\
& Urate oxidase \\
Transferases & Transaminase \\
& Transglycosylase \\
Hydrolases & Acetylesterase \\
& Amylase \\
Asparaginase \\
Cellulase \\
Deamidase \\
Invertase \\
Galactosidase \\
Urease \\
Lipase \\
Protease \\
Pyrophosphatase \\
Nucleotidase
\end{tabular}

(a) From Burns (1986). 


\subsubsection{Carbon Transformations}

The most important element in the biosphere, and the foundation of the structure of all cells, is carbon. Inorganic $\mathrm{CO}_{2}$ is converted into organic forms by photosynthesis by plants and some microorganisms. These organic forms of carbon are subsequently used by animals in the generation of new cell material. After the death of plants, animals, and microbes, the metabolic activities of soil microorganisms transform this organic carbon into $\mathrm{CO}_{2}$, microbial biomass, and soil organic matter. The cycling of carbon is shown in Figure 3.1.

\subsubsection{Nitrogen Transformations}

Nitrogen has considerable biological and economic importance. As a key building block of proteins, it is an indispensable and often limiting component of plants, animals, and microorganisms, and vast quantities of nitrogen are used as agricultural fertilizers. As does carbon, nitrogen undergoes a variety of transformations in soil in which the element is shuttled between organic and inorganic forms (Alexander 1977). The microbial population of soil has an essential role in this cycle. Atmospheric $\mathrm{N}_{2}$ is converted to organic forms by the action of bacteria that are free-living or live in

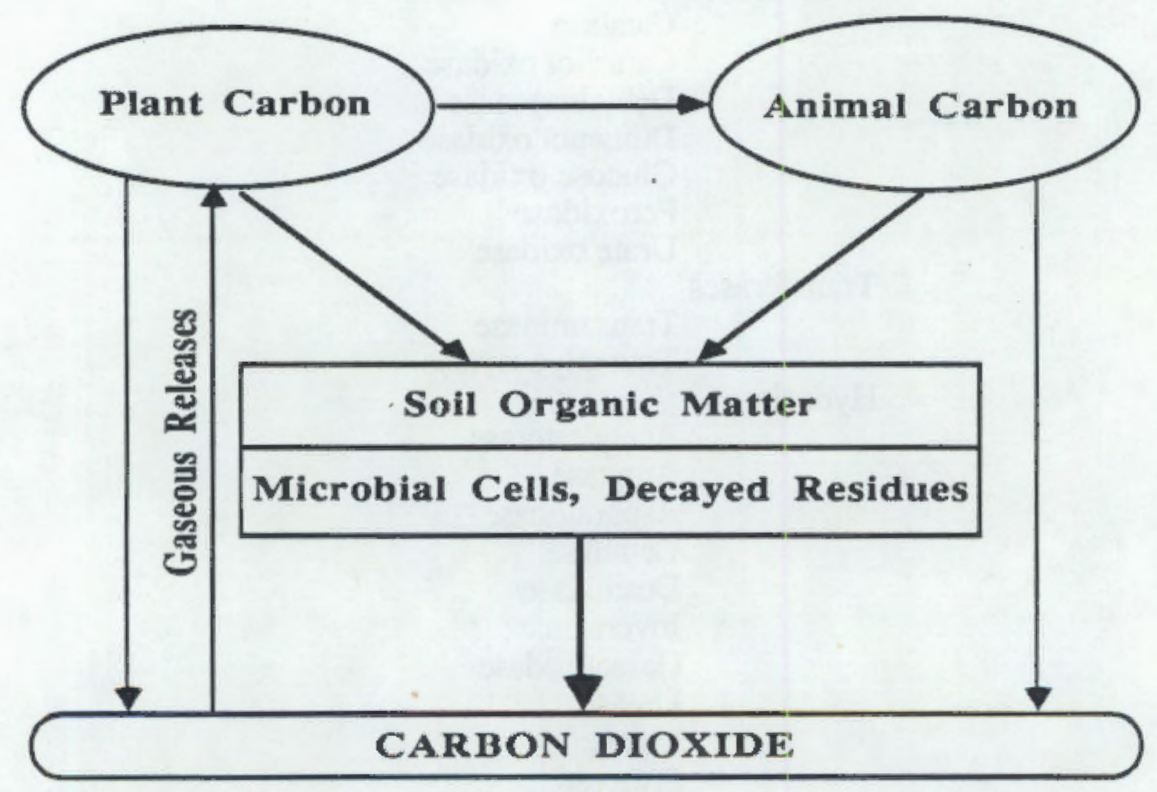

Figure 3.1. The Carbon Cycle (from Alexander 1977) 
symbiosis with plant roots or leaves. During the decay of plant, animal, and microbial biomass, the organic nitrogen is mineralized to ammonium, which can be immobilized by plants and microorganisms or oxidized to nitrate by autotrophic bacteria and some fungi. Nitrate can be lost from soil by leaching, which may cause groundwater pollution, can be immobilized by plants or microorganisms, or, under anaerobic conditions, can be utilized as the terminal electron acceptor by facultative anaerobic bacteria and thus be reduced to gaseous nitrogen compounds. Some gaseous nitrogen compounds are important atmospheric pollutants. The cycling of nitrogen is shown in Figure 3.2.

The mineralization, immobilization, and, to a limited extent, denitrification reactions of the nitrogen cycle are conducted by numerous microbial species. Therefore, as in carbon cycling, these reactions are not species specific, and monitoring these processes after the addition of a xenobiotic to soil does not indicate which microbial species are affected by the xenobiotic. In contrast, nitrification and nitrogen fixation result from the metabolic activities of highly specialized microbial groups. Therefore, monitoring the changes in the metabolic activities of these microorganisms enables the assessment of the effects on specific species by xenobiotics.

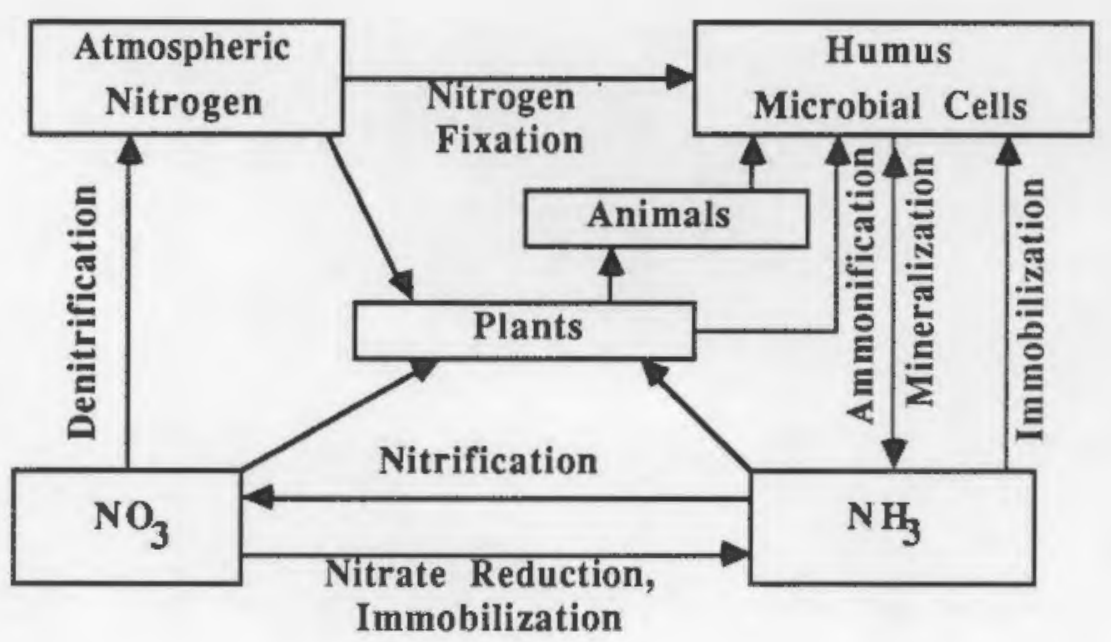

Figure 3.2. The Nitrogen Cycle (adapted from Alexander 1977) 


\subsubsection{Transformations of Other Elements}

Soil microorganisms also have an important role in the mineralization and transformation of other elements, such as phosphorus, sulfur, iron, and manganese, in addition to carbon and nitrogen. Phosphorus is often limiting for plant growth because the concentration of the major form of phosphorus available to plants $\left(\mathrm{PO}_{4}{ }^{3-}\right)$ is often very low. Soil microorganisms, particularly mycorrhizal fungi, can be important to the phosphorus nutrition of plants. Sulfur is cycled in the environment primarily through the activities of microorganisms that assimilate sulfate, mineralize organic sulfur compounds and liberate $\mathrm{H}_{2} \mathrm{~S}$, or oxidize $\mathrm{H}_{2} \mathrm{~S}$ to elemental sulfur or sulfate. Sulfate is also used by some strict anaerobic bacteria as a terminal electron acceptor. Iron and manganese, as well as some other metals, are cycled in the environment between their oxidized and reduced forms by the action of microorganisms that can use these elements as a source of electrons or as terminal electron acceptors (Atlas and Bartha 1987; Ghiorse 1984). 


\subsection{XENOBIOTICS}

Literally defined, "xenobiotic" compounds are chemicals that are foreign to the biosphere. Under this definition, many compounds, such as metals, some pesticides, and many nonpesticidal organic chemicals, cannot be considered xenobiotic because they occur naturally in the environment. However, this restricted definition fails to take into account the activities of man, which can increase the concentration of "natural" compounds in an environmental compartment to levels that cause undesirable effects. For example, the essential element phosphorus is not normally a xenobiotic. However, if it is released into aquatic environments in high concentrations, undesirable eutrophication results. Therefore, for the purposes of this review, the definition proposed by Hutzinger and Veerkamp (1981), i.e., that a xenobiotic is any compound released anthropogenically into an environmental compartment at a concentration that causes an undesirable effect, will be used.

\subsection{CLASSIFICATION AND SOURCES}

\subsubsection{Organic}

In terms of quantity produced, diversity, and potential adverse effects on the environment, the most important types of xenobiotic compounds are those of which the molecular structure is carbon based (i.e., organic). Sixty-five classes of organic compounds are considered hazardous, and of these, 114 organic compounds have been designated by the U.S. Environmental Protection Agency (EPA) as priority pollutants (Kobayashi and Rittmann 1982). Table 4.1 lists some examples of environmentally relevant organic compounds that have been detected in soil systems and which represent a potential hazard to this ecosystem.

A number of the compounds listed in Table 4.1 represent classes of compounds that are known or suspected carcinogens, teratogens, and/or mutagens. The halogenated organic compounds, especially the chlorinated aromatic compounds, are of particular 
Table 4.1. Examples of Important Xenobiotic Compounds

Compound type

Aliphatic (halogenated)

Aliphatic (nonhalogenated)

Aromatic (nonhalogenated)

Aromatic (halogenated)

Polycyclic (nonhalogenated)

Polycyclic (halogenated)

Pesticides

\section{Examples}

\author{
Trichloroethane \\ Trichloromethane \\ Methylene chloride \\ Tetrachloroethane \\ Acylonitrile \\ Toluene \\ Benzene \\ Nitrobenzene \\ Phenol \\ Cresol \\ Pentachlorophenol \\ Chlorobenzoate \\ Hexachlorophenol \\ Dichlorobenzoate
}
Napthalene
Benzo(a)pyrene
Anthracene
Biphenyl
Phenanthracene
Benzo(a)anthracene
PCBs
Toxaphene
Lindane
DDT
Heptachloroborane
Dieldrin
2,4-D

concern because of the deleterious effects many of these compounds have on biota and their recalcitrant behavior in the environment (Alexander 1977). Most chlorinated compounds were absent from the biosphere before their anthropogenic synthesis and, thus, can be considered to be true xenobiotics. Consequently, they persist in the environment because they are not susceptible to the normal rate of biological transformation (Reineke 1984). 
The agricultural industry is an important source of organic xenobiotic contaminants in soil systems. Other sources of organic xenobiotic compounds include sewage effluent disposal, sludge disposal, the petroleum industry (e.g., leakage from home fuel and service station storage tanks), the mining industry, and other nonagricultural industrial wastes (Keswick 1984). Figure 4.1 shows the distribution of hazardous waste generation by standard industrial classification. A classification system for herbicides, the most common of the agricultural chemicals, is provided in Table 4.2.

\subsubsection{Fossil Fuel-Related Xenobiotics}

Fossil fuels represent the major source of feed stocks for the production of organic chemicals. The large number and types of organic chemicals comprising this group make prediction of their behavior in soils extremely difficult. However, a classification scheme was developed to provide an approach for systematic study of a wide range of

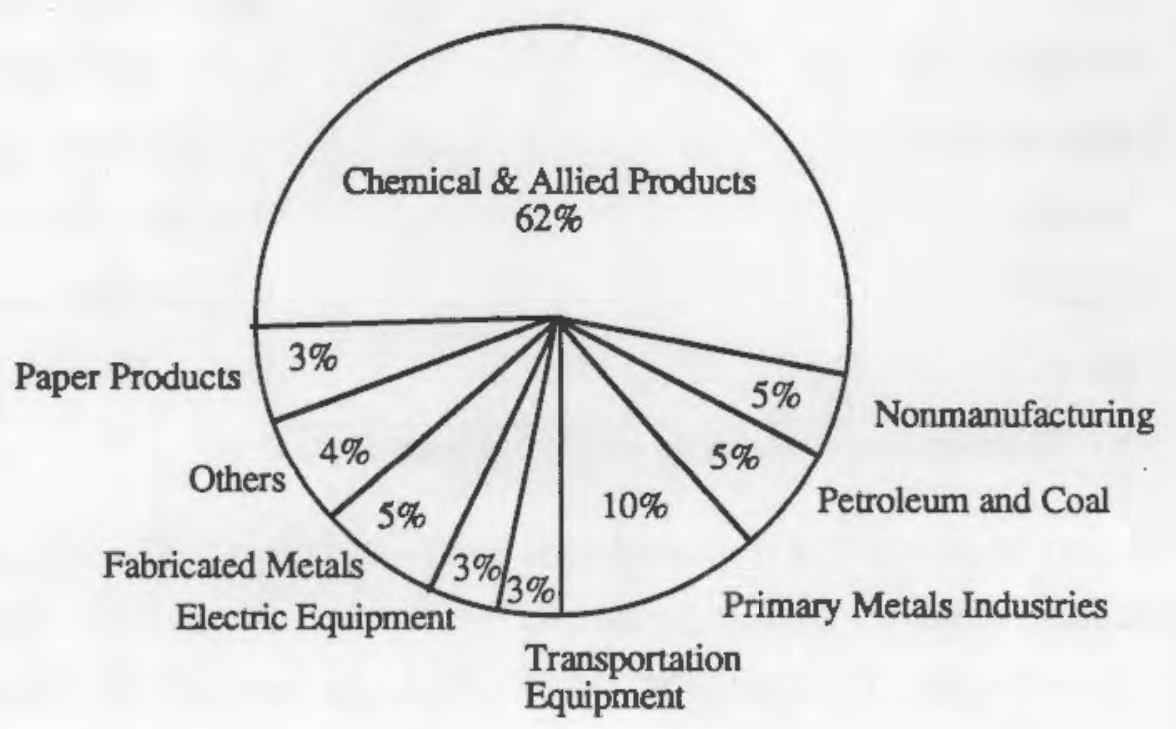

Figure 4.1. Percentage of Hazardous Substances Generated by Standard Industrial Classification in 1980 (based on Keswick 1984) 
Table 4.2. Classification of Herbicides Based on Chemical Group and.Class ${ }^{(a)}$

\begin{tabular}{lll} 
Chemical group & Chemical type & Representative compounds \\
\hline Aliphatics & $\begin{array}{l}\text { Chlorinated } \\
\text { Arsenicals } \\
\text { Other }\end{array}$ & $\begin{array}{l}\text { TCA, Dalapon } \\
\text { DSMA, MAA, MAMA, MSMA } \\
\text { Acrolein, Glyphosate }\end{array}$ \\
Amides & $\begin{array}{l}\text { Chloroacetamides } \\
\text { Other }\end{array}$ & $\begin{array}{l}\text { Alachlor,Metolachlor,Terbuchlor } \\
\text { Diphenamid, Propanil }\end{array}$ \\
Benzoics & & Dicamba, TBA \\
Bipyridiliums & & Diquat, Paraquat \\
Carbamates & & Barban, Propham \\
Dinitroanilines & & Benifin, Oryzalin, Trifluralin \\
Diphenyl ethers & & Fluorodifen, Nitrofluorofen \\
Hydrocarbon/oils & Unsaturated ring & Benzene, Naphthalene \\
& Saturated ring & Cyclopentane, Cyclohexane \\
Titriles & Unsaturated, polar & Brimethyl Benzene \\
Phenoxys & & Bromoxynil, Dichlorbenil \\
Thiocarbamates & & $2,4-D, 2,4,5-T$, Silvex \\
Triazines & & Cycloate, Vermolate, Metham \\
Uracils & & Atrazine, Desmetryn, Simazine \\
Ureas & & Bromocil, Terbacil \\
\hline
\end{tabular}

(a) Based on Hartley and Kidd (1983) and Beste (1983).

organic constituents using representative compound classes (Zachara et al. 1984). This classification scheme, similar to that for herbicides, is based on the physicochemical properties of organic residues (Table 4.3). Eight classes of compounds were selected, based on specific criteria. These criteria included:

1. the chemical composition of a wide variety of liquid wastes

2. potential environmental concentrations for individual classes

3. water solubility

4. chemical complexity. 
Table 4.3. Chemical Classification of Fossil Fuel-Related Organic Residues (aromatic classes and suitable representative compounds are listed in order of increasing complexity ${ }^{(a)}$ )

\section{Compound \\ class}

Representative compounds

Amine

Basic aromatic

$\mathrm{N}$-heterocycles

Phenols

Neutral aromatic

$\mathrm{N}$-heterocycles

Nitroaromatics

Thiophenes

Neutral aromatic hydrocarbons

Furans
Aniline, 1-Aminonaphthalene, 1-Aminoanthracene, 2-Aninobenzo(a)anthracene

Pyridine, Quinoline, Acridine, Benzo(a)acridine

Phenol, 1-Naphthol, 1-Hydroxyanthracene, 2-Hydroxybenzo(a)anthracene

Indole, Carbazole, Benzo(c)carbazole

Nitrobenzene, 1-Nitronaphthalene, 1-Nitroanthracene, 2-Nitrobenzo(a)anthracene

Benzo(b)thiophene, Dibenzo(b,d)thiophene, Benzo(b)naphtho(1,2-d)thiophene

Naphthalene, Anthracene, Benzo(a)anthracene

Benzo(b)furan,Dibenzo(b,d)furan,Benzo(b)naphtho(1,2)furan

(a) From Zachara et al. (1984).

\subsubsection{Inorganic}

Many inorganic compounds formed as waste products of modern industry, such as the oxides of sulfur and nitrogen, can be considered to be xenobiotics because of the elevated concentrations released and the deleterious effects that they have on the biosphere. However, the principal inorganic xenobiotic chemicals are the heavy metals and metalloids (Keswick 1984). Although many metals are reasonably abundant in the earth's crust, anthropogenic activities (including fuel combustion, mining, smelting, and agricultural practices) often increase their concentration to toxic levels. Metals that are toxic at sufficiently high concentrations and therefore are potentially hazardous include arsenic, boron, cadmium, chromium, copper, lead, mercury, molybdenum, nickel, selenium, tin, vanadium, and zinc (Babich and Stotzky 1982, 1985a; Chang and Broadbent 1982). 


\subsection{INTERACTIONS OF XENOBIOTICS WITH SOILS}

After xenobiotics are released into the environment, an irreversible chain of dynamic events is set into motion. The xenobiotic can modify the abiotic and biotic processes that occur in soil and can, in turn, be acted on by these processes. Many different interactions of xenobiotics with soils have been recognized (Figure 4.2). The chemical properties of the xenobiotic and its environmental concentration determine, to a large extent, the interactions that occur.

When a xenobiotic is released into soil, it may be transported or chemically modified by biotic or abiotic processes. The behavior of the xenobiotic will depend on its chemodynamic properties and on the physical, chemical, and biological properties of soil. Table 4.4 lists some of the processes that affect the behavior of a xenobiotic in soil.

Adsorption, leaching, bioconcentration, and volatilization are processes that affect the transport of the original compound within soil, whereas hydrolysis, oxidation-reduction, and microbial transformation affect its modification. However, these processes do not occur independently of one another, and the rate at and extent to which one process occurs will govern the rate and extent of other processes. For example, the adsorption of 2,4-D on clay minerals and organic matter has been shown to decrease its biodegradability (Ogram et al. 1985).

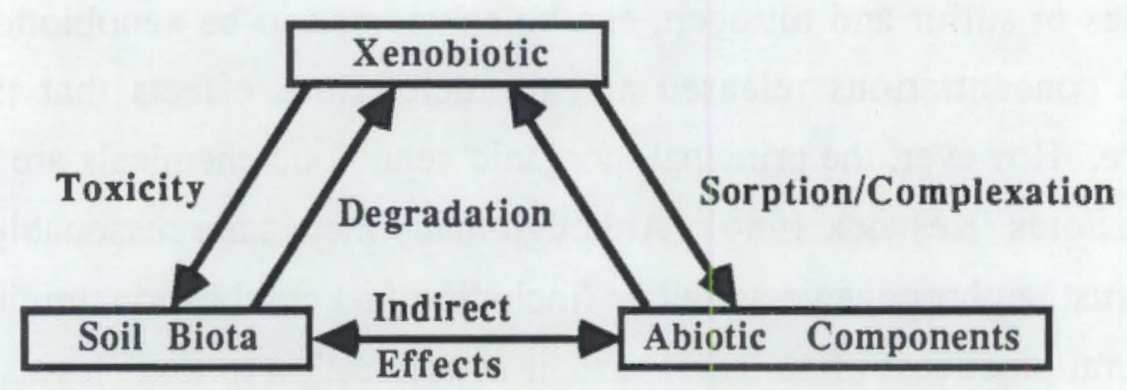

Figure 4.2. Interactions of Xenobiotic Chemicals with Soil 
Table 4.4. Processes in Soil That Affect the Behavior of Xenobiotics (a)

Process Governing factors

Hydrolysis $\quad \mathrm{pH}$

Microbial transformation

Presence of degradative enzymes; appropriate environmental conditions

Volatilizauion

Equilibrium vapor pressure

Oxidaion-reduction

Eh

Leaching

Solubility

Adsorption

Partition coefficient; $\mathrm{pK}_{\mathrm{a}}$ of adsorbate; types of adsorbents available; solubility

Bioconcentration

Partition coefficient; $\mathrm{pK}_{\mathrm{a}}$ of adsorbate

(a) Modified from Hulzinger and Veerkamp (1981).

The most versatile and active of systems that affect the modification of xenobiotics in soil are biotic (Tinsley 1979). Many xenobiotic compounds have little structural resemblance to natural compounds, and degradation of these xenobiotic compounds will be dependent on: 1) the ability of existing microbial enzyme systems to act on those xenobiotics that are similar, but not identical, to chemicals found in nature; or 2) the ability of the xenobiotic to induce the synthesis of necessary degradative enzymes. Biodegradation is less likely for a molecule with structural features seldom or never encountered in natural products. Some of the relationships between chemical structure and biodegradability are outlined in Table 4.5 .

In addition to the structural features of the xenobiotic, environmental conditions, such as the presence or absence of oxygen, the content of usable water, $\mathrm{pH}$, and temperature, must be conducive to the activity of those microorganisms containing the appropriate enzymes. A discussion of all possible transformations that could occur in soil is beyond the scope of this summary. However, some of the more common types of 
Table 4.5. Influence of Structure on Biodegradability of Xenobiotics (a)

Type of compound or substituents

Hydrocarbons

Aromatic substitutes

Aliphatic chlorine
More degradable

Higher alkanes $(\sim 12 \mathrm{C})$
Alkanes
Straight-chain
paraffinic
Paraffinic
mono- and bicyclic
aromatic

$-\mathrm{OH}$

$-\mathrm{COOH}$

$-\mathrm{NH}_{2}$

$-\mathrm{OCH}_{3}$

$-C l$ more than 6 carbon atoms from terminal C
Less degradable

Lower alkanes

High molecular

weight alkanes

Branched paraffinic

Aromatic

Polycyclic aromatic

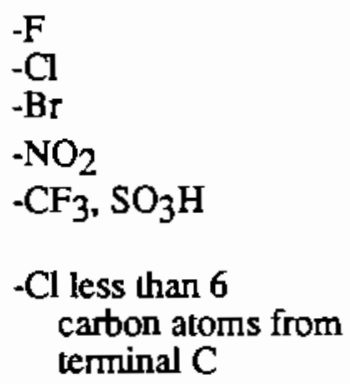

(a) From Hutzinger and Veerkamp (1981).

reactions catalyzed by microorganisms include dehalogenation, deamination, decarboxylation, methyl oxidation, hydroxylation, B-oxidation, reduction of triple and double bonds, sulfur oxidation, hydration of double bonds, polymerization, and nitro metabolism (Alexander 1981).

The effects of xenobiotics on the abiotic properties of soil, both physical and chemical, have not received much attention. Adsorption of a xenobiotic on mineral and organic surfaces can change the chemical properties of the soil by increasing or decreasing the $\mathrm{CEC}, \mathrm{AEC}, \mathrm{pH}$, and percent base saturation and by altering the hydrophilic/hydrophobic characteristics of the adsorbent (i.e., mineral or organic surface). Effects of xenobiotics on the physical properties of soil include: 1) changes in porosity by occupation of pore space, thereby reducing the ability of the soil to transmit water; 2) reduction in water-holding capacity caused by the exclusion of water; and 3 ) reduction in stability of soil aggregates, as a result of the disruption of mineral-organic 
matter interactions. In addition to the direct effects that xenobiotics can have on abiotic soil properties, they may also affect these properties indirectly. For example, bacteria using a xenobiotic as a nutrient source can cause a decrease in the hydraulic conductivity of soil by excreting metabolic products that clog soil pores (Frankenberger et al. 1979). 


\subsection{ENVIRONMENTALFACTORS THAT INELUENCE INTERACTIONS BETWEEN MICROORGANISMS AND XENOBIOTICS}

Interactions between xenobiotics and microorganisms in soil are influenced by a variety of environmental factors, such as $\mathrm{pH}$, Eh, temperature, water content, soil type, $\mathrm{CEC}$, and AEC. The influence of environmental factors on the growth and activities of microorganisms in soil has been studied and reviewed extensively (Atlas and Bartha 1987; Domsch et al. 1983; Doetsch and Cook 1974; Stotzky 1974). In addition, the abiotic factors that affect interactions between microorganisms and inorganic xenobiotics (e.g., heavy metals) have been reviewed by Babich and Stotzky (1982, 1985a). However, the influence of environmental factors on microbe-organic xenobiotic interactions has not received sufficient attention.

\subsection{PHYSICOCHEMICAL FACTORS}

\subsubsection{Clay Minerals}

The type and concentration of clay minerals present in a particular soil have a great effect on the toxicity of various inorganic and organic xenobiotics to microorganisms. Heavy metals can be adsorbed on clay minerals, thereby reducing their concentration in the soil solution and attenuating their adverse effect on microbial populations in soil (Stotzky 1986). The toxic effects of cadmium, lead, nickel, mercury, and zinc have been shown to be reduced in the presence of clays (Babich and Stotzky 1977, 1978, 1979, 1982, 1985a; Babich et al. 1983; Debosz et al. 1985; Stotzky 1986), primarily as a result of the CEC of the clays.

Few studies have investigated the effect of clay minerals on the toxicity of organic xenobiotics. Organic compounds, especially at $\mathrm{pH}$ values below their $\mathrm{pI}$, may be adsorbed on clay minerals, thereby reducing their inhibitory effects on microorganisms. Clay minerals have been shown to decrease the toxicity of some antibiotics and pesticides in soil (Stotzky 1986). On the other hand, adsorption of organic compounds on clay surfaces may increase toxicity by concentrating the compound in the region of high microbial density; however, this hypothesis has not been proven. 
In addition to a CEC, clays also have an AEC, the magnitude of which is dependent on the $\mathrm{pH}$ of the soil. The AEC of clay minerals can be important in the adsorption of anionic xenobiotics.

\subsubsection{Organic Matter}

Organic matter contributes to both the CEC and the AEC of soil, and therefore the effect of this fraction on the toxicity of xenobiotics would be similar to that of clays. For example, organic matter has been shown to decrease the toxic effect of some heavy metals (Babich and Stotzky 1982), presumably, in part, by binding the heavy metals by an ion-exchange mechanism. In addition, soluble organic matter in the soil solution may reduce the toxicity of heavy metals by chelating the metal and thus reducing its availability to microorganisms (Babich and Stotzky 1985a; Stevenson and Finch 1986).

The behavior of organic xenobiotics may also be altered by the presence of organic

matter. Reduction in solution-phase concentration can occur through a variety of mechanisms, including ion exchange, protonation, covalent bonding, $\mathrm{H}$-bonding, van der Waals forces, and coordination through an attached metal ion (ligand exchange) (Stevenson 1985). In addition, nonpolar xenobiotics can be partitioned onto organic surfaces by hydrophobic mechanisms.

\section{$5.1 .3 \mathrm{pH}$}

The $\mathrm{pH}$ of soil affects interactions between microorganisms and xenobiotics in various ways. First, $\mathrm{pH}$ influences the sorptive behavior of both inorganic and organic compounds. For example, the adsorption of some heavy metals (e.g., copper, lead, zinc) increased with increasing $\mathrm{pH}$, whereas the adsorption of other metals (e.g., mercury) decreased with increasing $\mathrm{pH}$ (Farrah and Pickering 1978a,b). Adsorption of some organics is a function of their $\mathrm{pI}$; therefore, $\mathrm{pH}$ levels that increase the cationic nature of organic xenobiotics should increase their adsorption on clay and organic surfaces. Second, $\mathrm{pH}$ influences the chemical speciation, mobility, and toxicity of metals (Babich and Stotzky 1982) and, possibly, of organics. Third, the $\mathrm{pH}$ of soil can alter the $\mathrm{CEC} / \mathrm{AEC}$ ratio of organic matter and thus influence the binding of xenobiotics on this 
fraction. Fourth, $\mathrm{pH}$ affects the extent of complexation of metals with soluble organics. Fifth, the physiological state and the metabolic activities of microorganisms are affected by soil pH (Atlas and Bartha 1987; Babich and Stotzky 1982), and this can affect their sensitivity to xenobiotics.

\subsubsection{Temperature}

Temperature has been shown to modify the toxicity of some inorganic xenobiotics (Babich and Stotzky 1982). However, the particular effect depends on the metal and the organism. For example, the toxicity of chromium (III) to Navicula seminulum decreased as the temperature increased from 22 to $30^{\circ} \mathrm{C}$; however, the toxicity of chromium (III) to Cyclotella meneghiniana increased as the temperature increased from 5 to $25^{\circ} \mathrm{C}$ (Caims et al. 1978). Although these studies were performed in water, it is probable that similar relations exist in soil. Temperature probably also indirectly modifies the toxicity of an organic xenobiotic by altering the physiological state of the microorganisms and, thus, their sensitivity or resistance to the xenobiotic (Babich and Stotzky 1985b).

Few studies have been conducted to assess the effect of temperature on microbe-organic interactions. The solubility of most organics and thus availability decreases with decreasing temperatures (Tinsley 1979). Therefore, the toxicity of some organic xenobiotics may increase with increasing temperature, but increasing temperatures increases the volatility of organics. This would have the effect of transferring the organic from the soil solution into the soil atmosphere and, possibly, away from susceptible microorganisms.

\subsubsection{Redox Potential}

Most inorganic and organic compounds can either accept electrons and be reduced, or donate electrons and be oxidized. This alteration in oxidation state is important in Inicrobe-xenobiotic interactions because the oxidized or reduced form of the xenobiotic often affects its toxicity and environmental behavior (e.g., adsorption, volatility, solubility). In addition, the redox potential can affect the types of microorganisms active in soil and thus the susceptibility of populations at given times. 
Numerous studies have examined the effects of microbial activity on the degradation and fate of organic compounds under different redox conditions (e.g., Gibson 1984); however, few studies have examined the effects of redox potential on the toxicity of xenobiotics to microorganisms. Nevertheless, redox potential may be an important factor in influencing the toxicity of organic xenobiotics to microorganisms in soil.

\subsubsection{Interactions Among Xenobiotics}

Xenobiotics are rarely, if ever, present in soil as individual constituents. Xenobiotic interactions, whether synergistic, additive, or antagonistic, are likely to affect microorganisms differently than a particular xenobiotic individually. Examples of synergistic, additive, and antagonistic interactions between heavy metals have been reviewed by Babich and Stotzky (1982). Antagonistic interactions can result from competition between cations for common sites on the surface of a susceptible microorganism, whereas synergistic or additive effects may result from the increased adsorption of one metal onto the cell caused by the presence of another metal (Babich and Stotzky 1982). Possible synergistic, additive, or antagonistic interactions between organic xenobiotic have received little attention (Babich and Stotzky 1985b). Nevertheless, organic-organic interactions probably have a major influence on the susceptibility of microorganisms to particular xenobiotics.

In closing this section of the review, it should be emphasized that more research is needed to determine the influence of physicochemical factors on interactions between microorganisms and xenobiotics in soil, especially organic xenobiotics. Better understanding of the physicochemical characteristics of a particular soil that affect microbe-xenobiotic interactions is necessary to develop models for predicting the effects of xenobiotics (existing and new) in different soils, which can then be used to identify "high-risk" and "low-risk" soils, i.e., those soils that accentuate or attenuate the effects of a particular xenobiotic (Babich and Stotzky 1982). One benefit gained by this understanding would be help in designing and siting new industries to match deleterious manufacturing outputs with soil types capable of reducing the adverse effects of the outputs. For example, because the toxic effects of a number of heavy metals are reduced 
in soils having a high CEC (Stotzky 1986), it would be wiser to place new refineries at locations where the surrounding soils contain clays that have a high CEC rather than where the soils are dominated by sand or clays having a low CEC. In addition, an understanding of the influence of physicochemical factors on microbe-xenobiotic interactions would help in modifying existing facilities to handle their pollutant output in a manner more environmentally sound and in detoxifying soils already polluted by xenobiotics (Babich and Stotzky 1982, 1983, 1985a). 



\subsection{EFFECTS OF XENOBIOTICS ON MICROORGANISMS IN SOL}

Xenobiotics, particularly pesticides, are often applied directly to soil to control organisms considered deleterious to agricultural crops, livestock, and humans. In addition, large quantities of organic and inorganic compounds enter the soil from the disposal of waste products from industrial, energy, agricultural, domestic, and national defense programs. There is concern among soil microbiologists and other scientists that, once in the soil, these compounds may adversely influence the growth and activity of beneficial indigenous microorganisms. The majority of biochemical transformations in soil result from microbial activity (Alexander 1977), and any compound that alters the number or activity of microbes could affect soil biochemical processes and, ultimately, influence soil fertility and plant growth.

\subsection{MICROBIOLOGICAL PROCESSES}

\subsection{Microbial Respiration}

Carbon dioxide $\left(\mathrm{CO}_{2}\right)$ evolution and oxygen $\left(\mathrm{O}_{2}\right)$ uptake are frequently used to assess the effect of xenobiotics on the overall metabolic activity of the soil microbial population. Respiration is nonspecific, and estimations of this process give no indication of the selective suppression of sensitive species. Therefore, cautious interpretation of experimental results is necessary.

There is little doubt that xenobiotic compounds can influence soil respiration. However, the specific influence (whether stimulatory or inhibitory) depends on the type of compound, its concentration, and the particular physicochemical factors of the soil to which the compound is added.

6.1.1.1 Type of Compound. It is difficult to determine from the literature a clear relation between compound structure and its effect on microbial processes, such as respiration. In general, low concentrations of recalcitrant compounds, such as the chlorinated aromatic hydrocarbons, exert little influence on soil respiration (Parr 1974), 
indicating that they are not toxic and do not serve as a carbon source and, thus, do not influence $\mathrm{CO}_{2}$ production or $\mathrm{O}_{2}$ consumption. However, at higher concentrations, chlorinated aromatics are toxic to microorganisms (Boyd and Shelton 1984), and thus inhibition of soil respiration is to be expected. For example, pentachlorophenol at 200 Ppm has been reported to inhibit completely $\mathrm{O}_{2}$ uptake by soil (Grossbard 1976). Less persistent organic compounds, such as the carbamate and phenylurea pesticides, appear to depress respiration; however, their effect is also concentration dependent (Bartha et al. 1967). Soil respiration is depressed to the greatest degree by the nonselective eradicant-type orgaric compounds, such as fungicides (Parr 1974).

At low concentrations, other organic xenobiotic compounds have been shown to stimulate $\mathrm{O}_{2}$ consumption (Grossbard 1976), possibly because these compounds are utilized as a carbon and/or energy source or because of the solubilization of soil organic compounds by the added organic xenobiotic and their subsequent utilization by the microbial biomass. The increase in $\mathrm{O}_{2}$ consumption may also be caused by the uncoupling of oxidative phosphorylation from the electron transport chain, thereby increasing microbial $\mathrm{O}_{2}$ consumption; this was suggested because the initial stimulation of $\mathrm{O}_{2}$ uptake by some compounds is followed by a marked inhibition (Bartha et al. 1967).

The inhibitory effect of xenobiotics is often temporary, and after inhibition, respiration often tends to increase above the controls (Wainwright 1978), probably as the result of an initial kill of some soil microorganisms by the xenobiotic followed by utilization of the dead microbial tissue as substrate by surviving microbial populations. This phenomenon has been used as the basis of the soil fumigation method for the estimation of total microbial biomass in soil (Jenkinson and Powlson 1976). A temporary depression in soil microbial activity may be beneficial from an economic standpoint, because soil microorganisms often compete with agronomic plants for vital nutrients. If the reduction in soil microbial activity coincides with a critical stage in the growth of a crop, the plant may be better able to compete for these nutrients. 
6.1.1.2 Concentration. The concentration in soil of a xenobiotic determines whether it will affect soil microbial respiration. At sufficiently high concentrations, few xenobiotics are without effect (Grossbard and Davies 1976), whereas at low concentrations, most xenobiotics have few acute inhibitory effects on soil respiration (Gaur and Misra 1977). However, little is known about the chronic effects of repeated applications of low concentrations of xenobiotics on soil microorganisms. Contradictory results have been obtained with the same compounds (Table 6.1).

6.1.1.3 Environmental Parameters. Some of these discrepancies can be explained by differences in the soil type used in the research. The "effective concentration" (i.e., solution-phase concentration) of metals, such as cadmium or zinc, is a function of the $\mathrm{pH}$ of the soil solution and the availability of cation- or anion-exchange sites. Soil $\mathrm{pH}$ influences the speciation form of the metal, which, in tum, influences the charge and, therefore, whether the metal adsorbs to cation- and anion-exchange sites on clay minerals or organic colloids. The CEC or AEC of soil will determine the extent of adsorption. Soils with a high exchange capacity would bind these metals to greater extent, thus lowering their availability to susceptible microbial populations. Organic compounds, such as simazine, usually bind on soil organic matter, thus, soils with high content of organic matter would be more effective in lowering the toxicity of added organic

Table 6.1. Variations in the Effects of Selected Xenobiotics on Soil Respiration

Compound Concentration Effect Reference

(ppm)

\begin{tabular}{lrll}
\hline Simazine & $8,000.0$ & $\begin{array}{l}\text { None } \\
\text { Inhibition }\end{array}$ & $\begin{array}{l}\text { Grossbard (1976) } \\
\text { Wainwright (1978) } \\
\text { Smith and Weeraratna (1974) } \\
\text { Stimulation }\end{array}$ \\
Cadmium & 5.0 & None & Bewley and Stotzky (1983) \\
& $1,000.0$ & Inhibition & Doelman and Haanstra (1984) \\
Zinc & $1,000.0$ & None & Bewley and Stotzky (1983) \\
& $1,000.0$ & Inhibition & Doelman and Haanstra (1984)
\end{tabular}


xenobiotics. Other environmental factors that influence the effect of xenobiotics on soil respiration include $\mathrm{pH}, \mathrm{Eh}$, ionic composition, temperature, and water content (Babich and Stotzky 1982; Grossbard 1976).

Time is a factor often overlooked. The effect of most xenobiotic compounds on soil microbial processes, such as respiration, is time dependent (Babich et al. 1983). For example, Doelman and Haanstra (1984) examined the long- and short-term effects of cadmium, chromium, copper, nickel, lead, and zinc on soil microbial respiration and found that the reduction in respiration caused by these metals remained significant even after 18 months. In contrast, Babich et al. (1983) and Debosz et al. (1985) found that the inhibitory effects of some heavy metals were transitory. For this reason, Domsch et al. (1983) suggested that specific monitoring periods be established in assessing the effect of xenobiotics on microbial populations: effects lasting less than 30 days can be considered negligible; effects lasting to 60 days, tolerable; and those effects extending over more than 60 days, critical. These guidelines were based on the time required (estimated at 30 days) for microbial communities to recover from natural stress events, such as fluctuations in temperature, $\mathrm{pH}$, and water content.

\subsubsection{Carbon Transformations}

Soil respiration provides an overall indication of the effects of xenobiotic compounds on soil microbial activities. However, it is also important to determine their effects on the utilization of specific carbon compounds. The breakdown of cellulose is particularly important, because it is the principal component of plant litter. The assessment of the effects of xenobiotic compounds on cellulose degradation would, therefore, indicate the extent to which these compounds influence the ability of indigenous microorganisms to decompose organic matter.

Inasmuch as the initial decompositions of cellulose is usually attributed to soil fungal populations, it is not surprising that fungicidal compounds have the greatest impact on cellulose degradation (Grossbard 1976). Nonfungicidal compounds, such as herbicides, have also been shown to inhibit cellulose degradation (Wainwright 1978). Grossbard 
(1973a,b) used buried calico strips and cellulose powder to examine the effects of 50 and $500 \mathrm{ppm}$ aminotriazole, Linuron, and Metoxuron. The assessment of cellulolytic activity was made by measuring the tensile strength of the calico strips after incubation. In general, these organic compounds inhibited cellulose degradation at the high concentration but had no effect at concentrations closer to field rates ( $50 \mathrm{ppm}$ ).

Certain heavy metals also inhibit the cellulolytic activity of soil-derived organisms. In experiments in which the activity of cellulose-decomposing fungi was assessed by measuring the release of dye from remazol blue-dyed cellophane films overlaid on an agar medium, Khan and Frankland (1984) observed that zinc, copper, nickel, lead, and cadmium inhibited cellulolytic activity at all concentrations tested (10 to $1000 \mathrm{ppm})$. The degree of inhibition varied, depending on the concentration and type of metal applied. For example, cadmium appeared to be much more toxic than lead. The inhibition of cellulolytic activity in soils by heavy metals has also been observed by Martin et al. (1982) and Tyler (1975).

\subsubsection{Nitrogen Transformations}

The transformation of organic nitrogen to inorganic forms is an important microbial function contributing to the fertility of soil and a transformation that has become a major indicator in assessing the effects of xenobiotics. The major nitrogen transformations mediated by soil microorganisms include ammonification, nitrification, denitrification, and nitrogen fixation (see Figure 3.2, page 15). Ammonification, nitrification, and nitrogen fixation represent input processes in which nitrogen is converted to forms available for uptake by plants. Denitrification is an output process in which inorganic nitrogen is reduced to gaseous products by facultative bacteria that use it as a terminal electron acceptor, thereby causing it to be lost from soil.

Ammonification, the production of ammonium-N from organic forms such as proteins, amides, and amino acids, does not generally appear to be inhibited by organic xenobiotic compounds and, in many cases, appears to be stimulated. For example, herbicides and insecticides have been shown to have little influence on ammonification (Anderson and Drew 1976; Wainwright 1978), whereas fumigation generally resulted in 
an increase in ammonium-N (Rovira 1976). The reasons for these observations are not clear, however, because a large and diverse group of microorganisms are capable of ammonification. The observed increases in ammonium $-\mathrm{N}$ after the addition of fumigants may also result from the release of ammonium-N from microorganisms killed by the compounds.

Nitrification is the process by which ammonium- $\mathrm{N}$, released after the mineralization of $\mathrm{N}$-containing organic compounds, is oxidized to nitrate in two steps (equations 1 and 2), most commonly by two genera of autotrophic bacteria:

$$
\begin{aligned}
& 2 \mathrm{NH}_{4}^{+}+3 \mathrm{O}_{2}=4 \mathrm{H}^{+}+2 \mathrm{H}_{2} \mathrm{O}+2 \mathrm{NO}_{2}^{-} \text {by Nitrosomonas sp. } \\
& 2 \mathrm{NO}_{2}^{-}+\mathrm{O}_{2}=2 \mathrm{NO}_{3}^{-} \text {by Nitrobacter sp. }
\end{aligned}
$$

Inasmuch as nitrification is usually conducted by a select group of chemoautotrophic microorganisms, it would be expected that this process would be much more sensitive to the action of xenobiotics than processes such as ammonification, which are conducted by a diverse microbial population. Indeed, Parr (1974) suggested that nitrification is one of the soil microbiological transformations most sensitive to pesticides.

Chlorinated hydrocarbons appear to have few acute effects on soil nitrification when applied at low rates. However, long-term chronic effects may result from repeated application of these pesticides. More information is needed concerning the chronic versus acute effects of xenobiotics on microorganisms in soils. In addition, the degradation products of chlorinated compounds may influence nitrification. Corke and Thompson (1970) studied the effects of selected chlorinated aromatic compounds on the oxidation of ammonium and nitrite and found that specific degradation products inhibited each process to a different degree. Their results, using Diuron and Propanil, along with the probable degradation products of each of these compounds are illustrated in Figure 6.1. The principle illustrated in Figure 6.1 is that degradation products of xenobiotics can affect specific microbial transformations, even if the parent xenobiotic has no effect. Therefore, a more critical evaluation of xenobiotic compounds in this regard is 

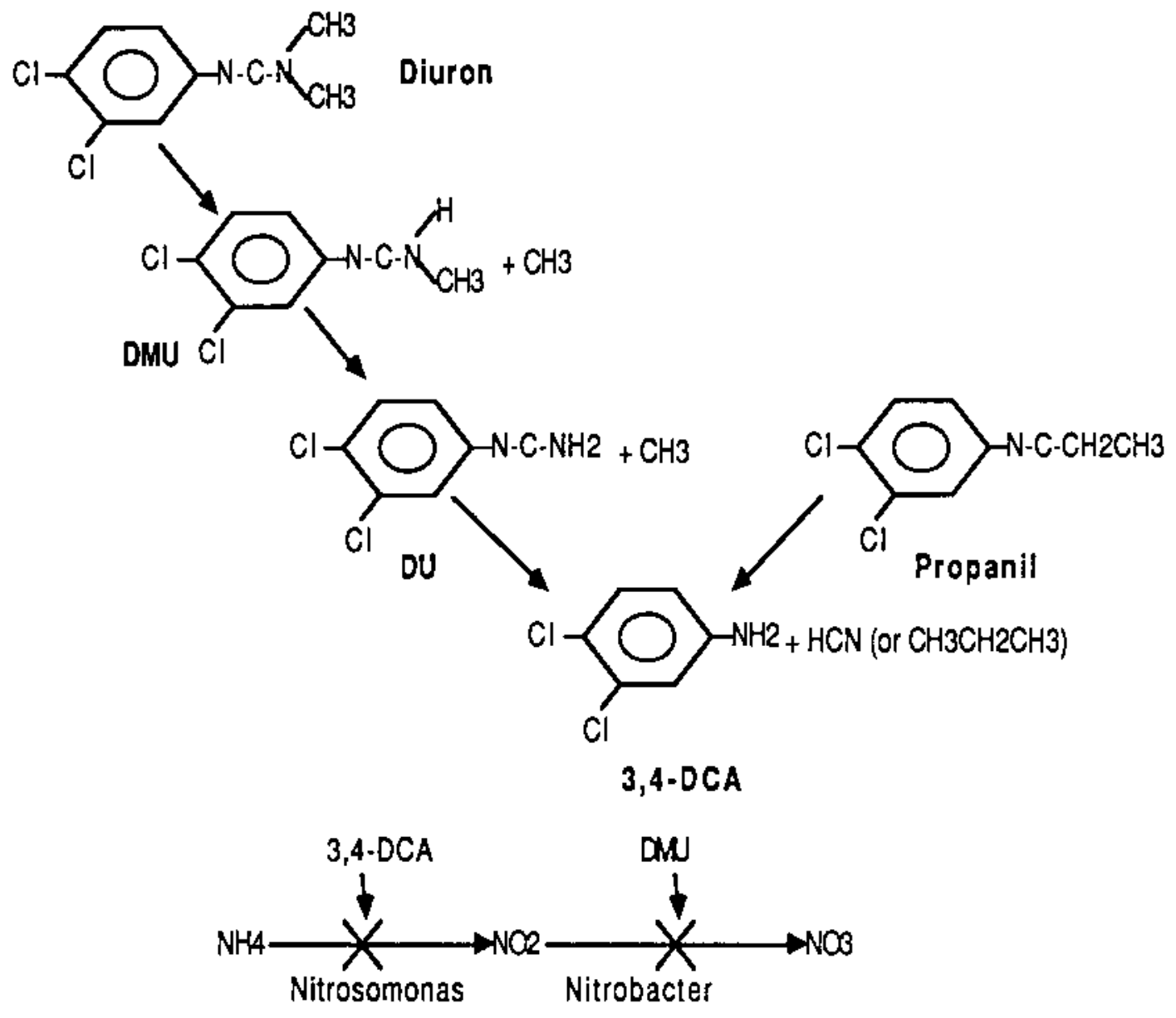

Figure 6.1. Inhibition of Soil-Nitrifying Bacteria by Degradation Products of Diuron and Propanil (from Corke and Thompson 1970)

advisable. In addition, the ramifications of inhibiting ammonium oxidation are much less than inhibiting nitrite oxidation. Nitrite is highly toxic to many plant and animal species, including man, and therefore processes that inhibit its oxidation without inhibiting ammonium oxidation could have adverse health affects.

Fungicides appear to have a greater initial and longer lasting effect on nitrification than most other classes of xenobiotics even though their target (e.g., fungi) is not considered important to the nitrification process (Parr 1974). The reasons appear to be 
twofold. First, these compounds are usually applied at much higher rates than other compounds, and second, they are designed and selected to affect microorganisms. In addition to the inhibitory effects of organic compounds, nitrification processes are, in general, also inhibited by the action of heavy metals (Giashuddin and Cornfield 1979; Rother et al. 1982; Chang and Broadbent 1982; Bewley and Stotzky 1983). The comparative toxicity of metals to nitrification follows the sequence, $\mathrm{Hg}>\mathrm{Cr}>\mathrm{Cd}>\mathrm{Ni}>$ $\mathrm{Cu}>\mathrm{Zn}>\mathrm{Pb}$ (Liang and Tabatabai 1978).

An interesting observation is the effect of xenobiotics on nitrification processes in soils differing in their "inherent nitrifying capacity." Dubey (1969) defined "inherent nitrifying capacity" as a soil's ability to support and maintain a large population of active nitrifiers. Both Dubey and Rodriguez (1970) and Parr (1974) observed that soils of high nitrifying capacity are affected less by xenobiotics than soils of low nitrifying capacity. These results may explain some of the discrepancies between experiments and emphasize the need to understand thoroughly the environmental parameters of the soils being evaluated.

Although the effects of xenobiotics on denitrification processes in soils have not been investigated throughly, Wainwright (1978) suggested that changes in nitrate-N caused by additions of xenobiotic compounds may result from changes in denitrification processes. For example, Saive (1974) found that although treatment of soil with Benomyl and Fentin hydroxide resulted in similar increases in nitrate levels, different processes were affected. Benomyl appeared to enhance the oxidation of nitrite to nitrate, whereas Fentin hydroxide appeared to decrease the rate of denitrification. The inhibitory effect of a number of other organic compounds, including many chlorinated compounds, on denitrification processes has also been demonstrated (Bollag and Henninger 1976; Bollag and Nash 1974). Both nitrification and denitrification are also sensitive to heavy metals: the sequence of toxicity is $\mathrm{Cd}>\mathrm{Zn}>\mathrm{Cu}>\mathrm{Pb}$ (see Babich and Stotzky 1985a). From an agronomic perspective, the loss of gaseous nitrogen caused by microorganisms under anaerobic conditions is undesirable; therefore, inhibition of denitrification may not be detrimental. 
The atmosphere is the principal source of nitrogen for plant growth. The microorganisms involved in fixing $\mathrm{N}_{2}$ are either free living, such as cyanobacteria, Azotobacter sp., Azospirillum sp., and Clostridium sp., or exist in symbiosis with higher plants, such as Rhizobium sp. and Frankia sp. The effects of xenobiotics on nitrogen fixation appears to be species specific. For example, symbiotic nitrogen-fixing bacteria appear to be more sensitive to the action of added compounds than free-living bacteria such as Azotobacter sp. (Grossbard 1976). Intraspecies sensitivity is also variable. For example, some strains of the blue-green alga Nostoc sp. can tolerate up to 2000 ppm Propazine, whereas other strains are killed by 1 ppm (Grossbard 1976).

Nitrogen fixation is often assessed by relatively nonselective methods, such as the acetylene reduction assay (Weaver and Frederick 1982). In the case of symbiotic nitrogen fixation, a distinction must be made between the response of the bacterium and of the host to a xenobiotic. For example, a compound that does not affect nitrogen-fixing bacteria directly may do so indirectly by inhibiting the host. This is reflected in the conclusions of Greaves et al. (1980) that the most reliable indications of the effects of xenobiotic compounds on symbiotic nitrogen fixation were obtained from measurements of plant growth and yield rather than specific nitrogen-fixation assays. However, it was suggested that if effects were found using plant growth and yield measurements, further investigations using acetylene reduction methods should be undertaken. Nevertheless, it should be emphasized that the examination of the effects of xenobiotics on symbiotic nitrogen-fixing bacteria independent of the host is important, because the bacteria may exist in soil for long periods of time in the absence of the host.

\subsubsection{Transformation of Sulfur and Phosphorus}

Sulfur enters soil primarily in the form of plant residues, animal wastes, chemical fertilizers, and rainwater. A large part of the sulfur in the soil profile is present in organic matter. The importance of microbially mediated transformations of sulfur has become increasingly apparent in recent years (Alexander 1977; Granat et al. 1976). Sulfate is the principal plant-available source of sulfur, and the oxidation of sulfur to sulfate and the reduction of sulfate are particularly important. The oxidation of sulfur 
involves principally the activity of specialized chemoautotrophic bacteria, although heterotrophic microorganisms may be important under certain conditions.

Because of the role of microorganisms in the transformation of sulfur and the recognized deficiencies of sulfur in various parts of the world (Coleman 1966), the effects of xenobiotics on sulfur transformation have become an important issue. Despite recognition of this importance, there have been few studies on the influence of xenobiotics on sulfur transformations. Certain pesticides have been shown to decrease sulfur oxidation when added to soils. Tu and Miles (1976) reported that $2000 \mathrm{ppm}$ Aldrin and Dieldrin decreased the rate of sulfur oxidation for 2 months, whereas Audus (1970) reported no effect at this concentration. Herbicides, such as Paraquat and 2,4-D, have been shown to decrease the oxidation of sulfur, although it is not known if the decrease was the result of a direct action on the principal organisms responsible for oxidation or an indirect effect caused by the loss of plant exudates after the death of the plant (Tu and Bollen 1968).

Another major nutrient required by both plants and microorganisms is phosphorus. Phosphate exists in soils as inorganic forms and as organic forms that undergo mineralization (Alexander 1977). Microorganisms, especially mycorrhizal fungi, are important in the uptake of phosphorus by plants (Agrios 1978). Because of the importance of mycorrhizal fungi, it would be expected that fungicides decrease the amount of soluble phosphorus. However, Wainwright and Snowden (1977) showed that fungicides increased slightly the level of $\mathrm{CaCl}_{2}$-extractable phosphorus in soils, resulting in increased solubilization of added insoluble phosphates. These increases were associated with an increase in the population of phosphorus-solubilizing bacteria after soil treatment. The application of insecticides and herbicides has been shown to have little effect on either phosphorus mineralization from organic matter or solubilization from inorganic forms (Smith and Weeraratna 1974; Tyunyayeva et al. 1974).

Although few studies have investigated the influence of heavy metals on microbially mediated cycling of inorganic phosphorus, these processes appear, in general, to be inhibited in the presence of heavy metals (Juma and Tabatabai 1977; Capone et al. 1983). 


\subsubsection{Cell-Free Enzymes}

Many reactions involving the transformation of inorganic and organic nutrients in soils are catalyzed by enzymes that exist free in the soil solution or in association with clays or organic matter (Burns 1983). Although studies on the effect of xenobiotic compounds on soil enzymatic activity have been limited, the results show considerable variability with respect to the effect of a compound on the activity of soil enzymes.

Many xenobiotic compounds either stimulate or inhibit the activity of soil enzymes (Table 6.2), although some may exert only a negligible effect. Some enzymes, such as dehydrogenase and urease, appear to be more sensitive to xenobiotics than others. Grossbard (1976) suggested that the inhibition of the activity of these enzymes may result from the loss of vegetative cover after application of the selected herbicides rather than from a direct antimicrobial effect. However, Cole (1976) found that compounds such as the triazines had a direct bacteriostatic effect. Also, even though most xenobiotics do not appear to inhibit mineralization of nitrogen in soils, they do appear to inhibit urease and protease activity, which is essential to the mineralization of nitrogen. Another interesting observation is that while most enzymes studied appear to be inhibited by most xenobiotics studied, phosphatase activity is often stimulated.

\subsubsection{Microbial Populations}

6.1.6.1 Free-Living Populations. Table 6.3 summarizes reported effects of some xenobiotic compounds on selected microbial populations. It is difficult to reach any generalizations concerning the effects of xenobiotics on specific microbial populations; although some trends are evident, additional research into documenting the effects by chemical class is needed. In general, algae and photosynthetic bacteria appear to be more susceptible to xenobiotics than other groups, probably because many of the compounds that have been tested inhibit photosynthesis. Actinomycetes and saprophytic fungi appear to be more resistant to the action of xenobiotics, and for many of the compounds tested, an increase in their numbers was detected (Simon-Sylvestre and Fournier 1979). 
Table 6.2. Effects of Selected Xenobiotics on Soil Enzymatic Activity(a)

\begin{tabular}{|c|c|c|c|c|c|c|c|c|}
\hline $\begin{array}{l}\text { Compound } \\
\text { Class }\end{array}$ & 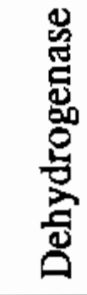 & \begin{tabular}{l} 
: \\
\multirow{2}{*}{} \\
岁
\end{tabular} & 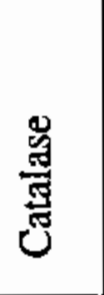 & 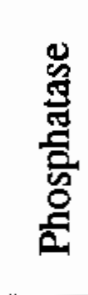 & 总 & 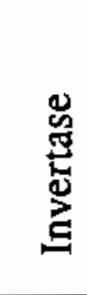 & 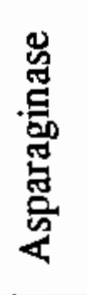 & 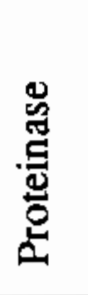 \\
\hline $\begin{array}{l}\text { Substituted } \\
\text { ureas }\end{array}$ & I & I & IS & $S$ & I & I & IS & UK \\
\hline Triazines & I & I & IS & $S$ & $r$ & $S$ & $S$ & I \\
\hline Nitrophenols & IS* & IS & I & UK & UK & * & UK & UK \\
\hline $\begin{array}{l}\text { Benzoic and } \\
\text { phenylacetates }\end{array}$ & I & I & $S$ & $S$ & UK & $S$ & UK & I \\
\hline $\begin{array}{l}\text { Heterocyclic } \\
\text { compounds }\end{array}$ & I & I & UK & $\mathrm{S}$ & I & I & UK & I \\
\hline Carbamates & $*$ & I & UK & $S$ & I & I & UK & UK \\
\hline Heavy metals & I & I & I & I & I & I & I & I \\
\hline
\end{tabular}

(a) Data from Grossbard (1976); Bonmati et al. (1985);

Wainwright (1978); Litchfield and Huben (1973).

$$
\begin{aligned}
& \mathrm{I}=\text { Inhibition } \\
& \mathrm{S}=\text { Stimulation } \\
& \mathrm{UK}=\text { Effects unknown } \\
& * \quad=\text { No effect }
\end{aligned}
$$


Table 6.3. Effects of Selected Xenobiotics on Soil Microbial Populations

\begin{tabular}{|c|c|c|c|c|c|c|c|c|c|c|}
\hline licrobial & 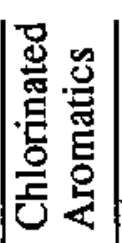 & 量 & 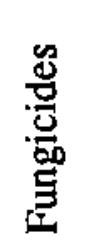 & 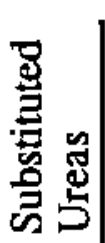 & 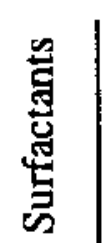 & 默 & $\ddot{g}$ & 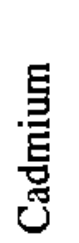 & 点 & 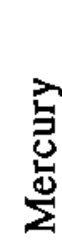 \\
\hline $\begin{array}{l}\text { Chemohetero- } \\
\text { trophic bacteria }\end{array}$ & ISN & I & SN & ISN & $I^{\wedge} S^{*}$ & $\mathrm{~N}$ & ISN & IN & IN & IN \\
\hline $\begin{array}{l}\text { Chemoauto- } \\
\text { trophic bacteria }\end{array}$ & IN & I & $\mathrm{N}$ & $?$ & $?$ & IN & IN & I & IN & IN \\
\hline Actinomycetes & $\mathrm{N}$ & I & $\mathrm{SN}$ & $\mathrm{SN}$ & $S$ & SN & $\mathrm{N}$ & IN & $\mathrm{N}$ & IN \\
\hline Rhizobia & I & I & I & I & $?$ & IN & $?$ & I & IN & I \\
\hline $\begin{array}{l}\text { Photosynthetic } \\
\text { bacteria }\end{array}$ & I & I & IN & ? & I & I & ? & I & IN & IN \\
\hline $\begin{array}{l}\text { Saprophytic } \\
\text { fungi }\end{array}$ & NS & I & I & IN & $S$ & $\mathrm{~N}$ & NS & IN & I & I \\
\hline $\begin{array}{l}\text { Mycorrhizal } \\
\text { fungi }\end{array}$ & IN & I & I & I & $?$ & IN & ? & IN & I & $?$ \\
\hline Algae & I & I & I & I & I & I & IN & I & I & I \\
\hline Protozoa & I & I & I & $?$ & $?$ & IN & IN & $?$ & IN & $?$ \\
\hline
\end{tabular}

(a) Adapted from Babich and Stotzky (1982); Simon-Sylvestre and Fournier (1979); Lal and Saxena (1982); Grossbard (1976); Parr (1974).

I = Inhibition

$S=$ Stimulation

$\mathrm{N}=$ No effect

$?=$ Unknown

$\hat{\wedge}=$ High concentrations only

* = Low concentrations only 
This trend, which was also seen with heterotrophic bacteria, may be related to two phenomena. First the xenobiotic in question served as a carbon or energy source for these microorganisms, in which case an increase in population density would occur. Second, the xenobiotic suppressed the population density of predatory microorganisms, such as protozoa. Another observation is that in general, compounds such as fungicides have a broad inhibitory effect, causing reduced population densities among all microbial groups. For certain groups, such as the heterotrophic bacteria, this effect is usually only temporary, and populations generally recover to or above pretreatment population densities. As mentioned earlier, this increase is usually attributed to the utilization, by surviving bacteria, of dead microbial cells killed by the xenobiotic.

6.1.6.2 Root-Associated Microbial Populations. Rhizosphere populations comprise a particularly important soil microbial community. Because of their unique relationship to the plant root zone that they colonize, rhizosphere microbial populations differ from those in soil not directly associated with roots (Gerhardson and Clarholm 1986). A small fraction of the carbon compounds resulting from photosynthesis are directly released by the roots into the rhizosphere. These organic compounds stimulate the microbial degradation of organic matter in soil adjacent to the roots, liberating inorganic nutrients that are available for direct uptake by the roots (Lynch 1983). The release of organic compounds by the plant also maintains the microbial interactions that may restrict the activities of plant growth-inhibiting microorganisms while sustaining the activities of plant growth-stimulating microorganisms (Schippers et al. 1986). However, very little is known about the effects of xenobiotics on release of root exudates and on plant pathogens.

Schippers et al. (1986) divided rhizosphere microorganisms into two groups with respect to their influence on plant development. The first group includes those organisms which, through their metabolic activities, stimulate the growth of plants. Included in this group are $\mathrm{N}_{2}$-fixing rhizobia, mycorrhizal fungi, free-living $\mathrm{N}_{2}$-fixers, and microorganisms that mineralize organic matter, liberating inorganic nutrients for plant use. The second group includes those organisms that inhibit plant growth, either directly, as in the case of plant pathogens, or indirectly, by inhibiting plant growth as a result of their metabolic activities. The loss of the first group of rhizosphere microorganisms through 
the action of xenobiotic chemicals can be detrimental to plant growth. However, it is the effect of xenobiotics on plant pathogens that has the greatest economic impact (Lynch 1983; Trappe et al. 1984; Roslycky 1985; Sanders 1986; Schippers et al. 1986).

Because rhizobia fix atmospheric $\mathrm{N}_{2}$ in symbiosis with leguminous plants, they are the most important among agriculturally beneficial soil bacteria (Roslycky 1985). The susceptibility of rhizobia to xenobiotics seems to vary with species, strain, type of chemical, and soil (Greaves et al. 1976). Once again, fungicides appear to have the greatest detrimental effect on rhizobia (Wainwright 1978). Although some herbicides have also been shown to inhibit rhizobia (Roslycky 1985; Barkay et al. 1986), rhizobia appear to be rather resistant to most herbicides (Greaves et al. 1976). Insecticides appear to have little inhibitory effect on rhizobia and, in some cases, can stimulate growth (Barkay et al. 1986). Heavy metals, particularly $\mathrm{Cd}, \mathrm{Hg}, \mathrm{Pb}, \mathrm{Cu}$, and $\mathrm{Zn}$, also have a detrimental effect of rhizobia (Babich and Stotzky 1982, 1985a).

Certain fungi also form symbiotic relationships with plant roots. These mycorrhizal fungi may be ectotrophic forms, in which the bulk of the fungus is outside the plant root, or endotrophic, in which most of the fungus is inside the plant tissue. The endotrophic forms of the vesicular-arbuscular (VA) types are increasingly recognized as being of significant importance in agricultural crops, as a result of their wide distribution and high efficiency in transporting phosphorus and other nutrients to the tissues of the host plant (Sanders 1986). Consequently, xenobiotics that affect mycorrhizal fungi will affect crop productivity. Similarly, xenobiotics that affect plant growth will affect formation of mycorrhizal associations.

Trappe et al. (1984) reviewed the effects of pesticides on mycorrhizal fungi. Not surprisingly, fungicides profoundly affect mycorrhizal fungi, as they are intended to kill fungi. However, most of the fungicides selectively affected some fungi more than others. For example, thiazoles were found to be particularly inhibitory to Zygomycotina and less inhibitory to most Basidiomycotina or Ascomycotina. The dicarboximide fungicides do not appear to inhibit mycorrhizal fungi, and some even stimulate these fungi. On the other hand, the dithiocarbamates seem to inhibit most mycorrhizal fungi. 
The effects of herbicides on mycorrhizal fungi can be twofold. First, mycorrhizal fungi can be drastically reduced by the herbicide directly. However, stimulatory effects have also been reported (Schwab et al. 1982). Second, because herbicides affect the growth and development of the host plant, their action on mycorrhizal populations can also be indirect. Schwab et al. (1982) suggested that the increase in mycorrhizae on plants treated with the herbicide, Simazine, resulted from the increased release of sugars and amino acids by the host. Similarly, inhibition of mycorrhizal fungi has been suggested to result from the reduction of sugar release by herbicide-treated plants (Trappe et al. 1984).

Effects of insecticides on mycorrhizal fungi have been studied least. As with other pesticides, the effects appear to depend on the type of compound as well as on the type of mycorrhizal fungi. The effects of heavy metals on mycorrhizae are also relatively unknown. However, chromium and cadmium have been shown to be inhibitory (Simon-Sylvestre and Fournier 1979; Babich and Stotzky 1985a).

It is difficult to quantify accurately microbial populations in soil because the ecological and physiological factors that control the growth of microorganism in soil are not well understood. Therefore, a completely accurate environmental risk assessment of the effects of xenobiotics on microbial populations and communities is not currently possible. Consequently, the quantification of microbial populations in soil as a measure of the effect of xenobiotics on microorganisms is often disregarded (Greaves 1982). Changes in microbial populations, if detectable, can serve as a guide in the interpretation of metabolic data, such as respiration or nitrogen transformations (Grossbard 1973b). In addition, results obtained from changes in species composition caused by the action of a particular xenobiotic may help to elucidate physiological factors involved in inhibition or stimulation. 


\subsection{MODE OF ACTION}

Present knowledge of the mechanisms whereby xenobiotics affect microorganisms is fragmentary. Specific cellular or biochemical responses will depend on the type of xenobiotic, as well as on the specific mictoorganism being affected. The types of cellular functions likely to be affected by xenobiotics include cell membrane permeability, photosynthesis, oxidative metabolism, and the synthesis of nucleic acids and proteins, as well as cellular function.

The interactions of xenobiotics (either through adsorptive or absorptive processes) with cell membranes appear to be important in determining the primary target of a xenobiotic. For example, Hicks and Corner (1973) showed that the lethal action of DDT on gram-positive bacteria was related to the binding of DDT to membranes of these bacteria. Later studies showed that DDT, as well as other chlorinated hydrocarbons, altered both the ratio of phospholipid head groups and the composition of fatty acids (Rosas et al. 1980). These changes might be expected to alter the structure and function of membranes, possibly resulting in bacterial death.

Some xenobiotic compounds have been reported to alter cellular morphology, in addition to biochemical changes. These alterations include abnormalities in nuclear morphology, such as deep incisions, loose chromatin, and fragmented macronuclei (Lal and Saxena 1980). Changes in the architecture of the plasma membrane, an altered number of cellular organelles, and damaged cell membranes causing leakage of cellular material have also been reported (Parasher et al. 1978).

Interference of xenobiotics with the structure and chemistry of membranes can affect the permeability of cells, which can, in turn, have serious effects on cellular activity. For example, certain chlorinated aromatics decreased the uptake of some amino acids, as well as the synthesis of proteins (Lal and Saxena 1982). In addition, the synthesis of nucleic acids was also inhibited by some chlorinated aromatics, such as DDT (Lal and Saxena 1979). Xenobiotics also inhibited the metabolism of a variety of compounds, including pyruvate, citrate, malate, lactate, succinate, and ethanol (Juneja and Dogra 
1978). The reduced metabolic capability has been attributed to the inhibitory effect of xenobiotics on the enzymes responsible for the catabolism of these compounds. For example, Chlordane has been shown to inhibit the activities of succinate dehydrogenase and other oxidative enzymes (Widus et al. 1971).

Various detrimental effects on photosynthetic microorganisms have been reported for certain xenobiotics, such as the chlorinated aromatics. This is particularly important because these microorganisms have an important role in primary food webs as well as in the oxygen balance of the biosphere. Clegg and Koevening (1974) showed that four organochlorine insecticides (DDT, Aldrin, Chlordane, and Dieldrin) significantly reduced the amounts of ATP detected in algae, suggesting that these compounds interfered with photophosphorylation in the light reaction of photosynthesis. In addition, the fixation of atmospheric $\mathrm{CO}_{2}$ was also shown to be inhibited by these compounds (Wurster 1968). 


\subsection{METHODS OF ASSESSING THE EFFECTS OF XENOBIOTICS ON MICROORGANISMS}

All known types of microorganisms, including bacteria, fungi, protozoa, and algae, occur in the soil (Alexander 1977; Lynch 1983). Bacteria and fungi are especially important because they comprise the majority of the microbial biomass in soil and are the primary contributors to the processes of decomposition of organic material, degradation of natural and anthropogenic organic chemicals, and cycling of humus (Lynch 1983). In addition, many of the important processes (e.g., nitrogen fixation, nitrification, sulfur oxidation) that occur in soils are mediated exclusively by specific groups of bacteria and/or fungi.

There is continuing concern that the accidental or deliberate release of xenobiotic compounds into soil may adversely affect the various segments of the soil microbiota, thus disrupting ecologically important microbe-mediated processes (e.g., nutrient cycling). Pesticides are effective in agriculture because they exhibit some degree of toxicity to biochemical processes and consequently have the potential for affecting nontarget microbiota. Many nonpesticidal organic compounds and heavy metals also affect microbial activity.

In assessing the effect of xenobiotics on soil microorganisms, three problems are immediately apparent: First, what is the effective concentration of the xenobiotic; second, which microbial processes or properties should be used to assess the effects of the compound in question; and third, which laboratory test system will allow an accurate estimate of the effect of the xenobiotic on a given process? Most xenobiotics have either an inhibitory or a stimulatory effect, depending on the concentration of the compound (Grossbard 1973b). However, the specific response to a concentration gradient is not determined by the amount of a xenobiotic applied to soil but by the amount with which the microbiota is in contact. Many xenobiotics often have low solubilities in water, they are adsorbed on mineral and organic surfaces, and their distribution in soil can be heterogeneous. In addition, the composition and density of microorganisms in soil are not uniform. Thus, the concentration of a compound to which different microbial 
populations are exposed will vary. To assess the effect of a particular compound on microorganisms in soil, an estimate of its concentration in soil is necessary.

It would be desirable to designate an indicator microbial property or process with which the overall effects of xenobiotics could be assessed. However, this is not possible, because different microbial processes are affected to different extents by various xenobiotics. For example, nitrifiers are more susceptible to fumigants than are ammonifiers and denitrifiers (Parr 1974). Therefore, to assess the effects of xenobiotic compounds on soil microorganisms, it is necessary to examine the effect of a xenobiotic on a variety of microbial processes and/or microbial species. Three categories of relevant indicators of the effects of xenobiotics on soil microorganisms have been suggested (Greaves 1982; Babich and Stotzky 1985a; Barkay et al. 1986): 1) assessment of the effects of xenobiotics on microbially mediated processes, such as respiration and transformations of nitrogen and carbon; 2) the effect of xenobiotic compounds on key soil enzymatic activities, such as those of phosphatase and urease; and 3) the influence of xenobiotics on specific microbial populations, especially those of rhizosphere bacteria and fungi because of their important role in increasing the availability and uptake of nutrients by plants.

\subsection{LABORATORY TEST SYSTEMS}

A variety of test systems are available for measuring the effects of xenobiotics on microorganisms in soil. Laboratory systems can range in complexity and size from simple batch systems employing domestic canning jars to complex mesocosms that use blocks of cropped soil housed in large greenhouses and are elaborately equipped with instrumentation to monitor a wide variety of microbial processes.

\subsubsection{Batch Systems}

In batch systems, soil is amended with the xenobiotic of interest and incubated in a closed system. An example of a batch system is the biometer flask developed by Bartha and Pramer (1965). This flask is a compact, commercially available unit used for measuring $\mathrm{CO}_{2}$ produced in soil by microorganisıns. Other inexpensive systems that are 
easy to construct and use for measuring $\mathrm{CO}_{2}$ evolution from soil are also available for testing the effects of xenobiotics (Anderson 1982). In addition, by using ${ }^{14} \mathrm{C}$-labeled substrates and monitoring the evolution of ${ }^{14} \mathrm{CO}_{2}$, the effects of xenobiotics on the mineralization of specific carbon compounds (e.g., cellulose) can be measured. Batch systems offer a simple and inexpensive means of assessing the effects of xenobiotics on microorganisms, which is particularly valuable because of the frequent need to monitor large numbers of samples and replicates, as well as many different xenobiotics. A major criticism of batch systems is that they fail to model adequately real ecosystems.

\subsubsection{Microcosms}

The use of terrestrial "microcosms" (Figure 7.1), or integrated laboratory model ecosystems, is an alternative approach to obtaining information about the impacts of xenobiotics on the biota and their interactions, as well as on the influence of abiotic factors on the degradation and residence time of a xenobiotic within a soil.

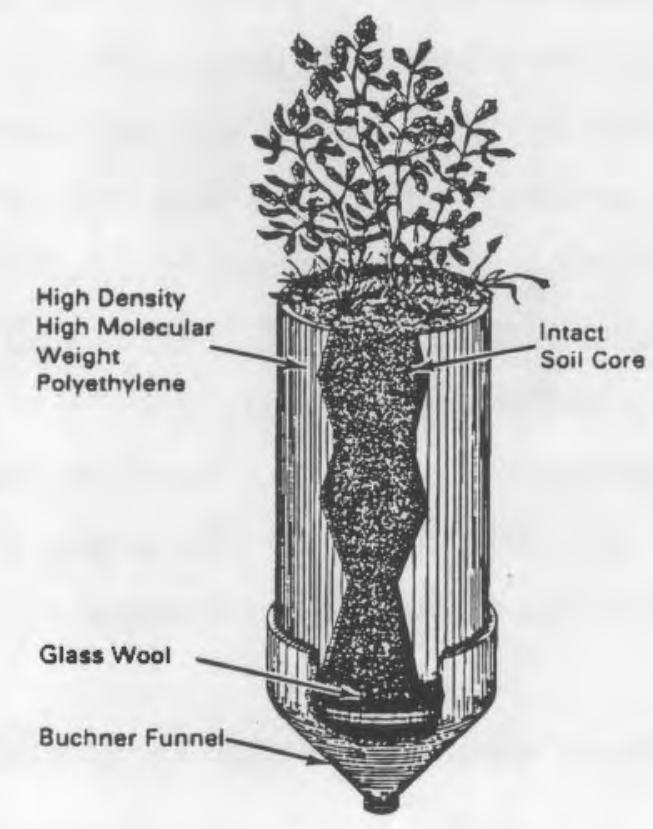

Figure 7.1. Terrestrial Soil-Core Microcosm Test System (Van Voris et al. 1985a) 
Simply defined, a microcosm is a small, controlled, laboratory system that mimics the processes and interactions in a larger natural ecosystem (Gillett and Witt 1979; Van Voris et al. 1985a). Its use to study the interactions and relations of organisms in their natural environment dates back to the mid-nineteenth century (Warington 1851, 1857). More recently, Beyers (1964) and Patten and Witkamp (1967), among others, developed the microcosm into a useful laboratory research tool. The application of this type of integrated test system to the questions of the ecological fate and effects of pesticides and complex chemical wastes came next (Metcalf 1977; Cole et al. 1976; Gillett and Gile 1976). This application resulted in a desire to make the test system as identical to the real world as possible and persuaded many scientists to incorporate larger and more complex components, such as fish, trees, and small mammals, into their laboratory model ecosystems. These "mesocosms" or "megacosms" outgrew most scientific laboratory buildings (Giesy 1980). Additionally, these "mesocosms" became too large to replicate to the degree required to obtain reasonable estimates of variance, and too expensive to operate and maintain.

For the smaller systems (e.g., Cole et al. 1976; Ausmus et al. 1979; Gile et al. 1979), the criticisms were 1) the microcosm did not represent its analog ecosystem; 2) a very large number of test units would be necessary to detect even large ecological effects; 3 ) the test system could not be used for chemicals that were environmentally persistent; and 4) the validity of the microcosm test system had not been demonstrated. The microcosm approach developed by Van Voris et al. (1985a) and described in a detailed protocol in EPA/600/3-85/047, ASTM 1988 Test Guideline E-1197, as well as in Federal Register $9 / 28 / 87$, Vol. 52 , No. 187 , pages 36363 to 36371 , overcomes many of the previous criticisms of the terrestrial microcosm test system. Based on research results compiled over a 5-year period on the "Terrestrial Soil-Core Microcosm" (Van Voris et al. 1984, 1985a,b; Tolle et al. 1981, 1983), this microcosm test system can be used to evaluate:

\section{1. fate of xenobiotics within the ecosystem:}

- transport between compartments

- transformation

- bioaccumulation

- chemical speciation 


\section{2. ecological effects of xenobiotics:}

- phytotoxic effects

- microbiological effects

- invertebrate effects

- community effects

- ecosystem effects (e.g., nutrient cycling)

\section{3. effects of xenobiotics on:}

- physicochemical properties of soils.

\subsection{METHODS FOR ASSESSING XENOBIOTIC IMPACTS ON RELEVANT MICROBIAL PROCESSES AND PROPERTIES}

It is beyond the scope of this section to consider in detail the methods available for studying the effect of xenobiotics on microorganisms in soil. Hence, overviews of methods used to measure important microbial processes and properties are presented. The methods most commonly used for determining whether a xenobiotic has an impact on microorganisms in soil include: 1) the measurement of microbial processes, such as respiration and the transformation of carbon and nitrogen and of other important elements, such as phosphorus and sulfur, 2) the measurement of soil enzymatic activities; and 3) the measurement of specific microbial populations.

\subsubsection{Respiration}

The uptake of $\mathrm{O}_{2}$ or the release of $\mathrm{CO}_{2}$ by bacterial, fungal, algal, and protozoan cells is used to measure the respiratory activity of microorganisms (Anderson 1982). Respiration is a measure of the overall activity of the soil microbiota and is frequently used to assess the effects of xenobiotics on the soil microbial community in both field and laboratory experiments. However, there are some problems associated with using respiration to measure the effects of xenobiotics on soil microorganisms. Measurement of respiration lacks specificity, because respiratory activities are not confined to 
microorganisms but occur also in animals and plants and as a result of abiotic chemical reactions. Therefore, it is difficult to assess whether changes in respiratory activities after the addition of a xenobiotic are microbial or nonmicrobial in origin. In addition, quantitative respiratory data do not always reflect shifts in microbial equilibria (e.g., changes in species composition), particularly if the compound in question is inhibiting to one microbial species but stimulating to another. Despite these problems, soil respiration is often used as an initial screening procedure for measuring the effects of xenobiotics on soil microorganisms because of the relative ease with which it can be measured (Bitton and Dutka 1986).

\subsubsection{Carbon Transformations}

The effects of xenobiotics on the transformations of organic matter is often monitored by measuring the evolution of $\mathrm{CO}_{2}$ from soils amended with plant material. The use of ${ }^{14} \mathrm{C}$-labeled substrates enables monitoring the effects of xenobiotics on the degradation of specific carbon compounds. Buried substrate techniques are also used to measure the effects of xenobiotics on the degradation of specific substrates. For example, the effect of xenobiotics on cellulose degradation in soil has been assessed by monitoring changes in the tensile strength of calico strips buried in soil (Grossbard 1973a). Another buried substrate technique uses fixed, unexposed color film to measure proteolytic activity in soil (Cullimore and Ball 1978). Proteolysis is measured by the mcrease in light transmission through the film resulting from degradation of the gelatin layers of the film (Greaves 1982).

\subsubsection{Nitrogen Transformations}

Ammonification and nitrification are often measured to assess the effects of xenobiotics on nitrogen transformations in soil (Greaves 1982). In one method, ground plant material is added to soil as a source of organic nitrogen, and the $\mathrm{NH}_{4}^{+}, \mathrm{NO}_{2}^{-}$, and $\mathrm{NO}_{3}^{-}$produced are measured (Greaves et al. 1980). If the xenobiotic has no effect, $\mathrm{NO}_{3}{ }^{-}$will accumulate. If ammonification is affected, the production of $\mathrm{NH}_{4}{ }^{+}, \mathrm{NO}_{2}^{-}$, and $\mathrm{NO}_{3}{ }^{-}$will be less than in the control soil. If nitrification is affected, $\mathrm{NH}_{4}{ }^{+}$accumulates. 
The effect of xenobiotics on denitrification can be examined by monitoring the production of $\mathrm{N}_{2} \mathrm{O}$ in sealed chambers enriched with acetylene $\left(\mathrm{C}_{2} \mathrm{H}_{2}\right)$ (Tiedje 1982). Another method uses gas chromatography to separate $\mathrm{N}_{2}, \mathrm{~N}_{2} \mathrm{O}$, and $\mathrm{NO}_{2}$ (Payne 1973).

The advantages and disadvantages of a variety of other methods, including ${ }^{15} \mathrm{~N}$ balance, the rate of $\mathrm{NO}_{3}-$ disappearance, and the rate of ${ }^{13} \mathrm{NO}_{3}-$ conversion to ${ }^{13} \mathrm{~N}_{2}$, are discussed by Tiedje (1982).

Nitrogen fixation by both symbiotic and free-living microorganisms can be monitored by the $\mathrm{C}_{2} \mathrm{H}_{2}$ reduction method (Weaver and Frederick 1982; Knowles 1982). $\mathrm{C}_{2} \mathrm{H}_{2}$ is reduced to ethylene $\left(\mathrm{C}_{2} \mathrm{H}_{4}\right)$ by the nitrogen-fixing bacteria, and the $\mathrm{C}_{2} \mathrm{H}_{4}$ is measured by gas chromatography.

\subsubsection{Transformations of Other Elements}

The effects of xenobiotics on the transformation of elements such as phosphorus, sulfur, iron, and manganese have not been studied in detail. However, simple soil incubation techniques with the extraction of the inorganic element of interest can be used to monitor the adverse or beneficial effects of a xenobiotic (Greaves 1982).

\subsubsection{Soil Enzymes}

A large number of cell-free enzymes that are active in soils have been described (Ladd 1978). Burns (1983) has separated these extracellular enzymes into seven different categories according to their source and location in soil systems:

1. enzymes whose normal functional location is within the cytoplasm of viable cells, yet remain active in dead cells and cell debris

2. periplasmic enzymes released into the environment by leakage through damaged cell membranes

3. enzymes attached to the outer surfaces of cell walls or associated with extracellular polysaccharides

4. enzymes that are truly extracellular and are secreted into the soil during cell growth 

5. enzymes temporarily associated with substrates as enzyme-substrate complexes
6. enzymes adsorbed to the clay constituents of soils
7. enzymes associated with colloidal organic matter.

More than 50 enzymes have been detected in soils (see Table 3.2), and many of these enzymes have a critical role in the cycling of nutrients. The sensitivity, accuracy, and ease of several enzyme assays have made them useful indicators of the effects of xenobiotics. In particular, the activities of phosphatases, dehydrogenases, and urease are frequently studied in assessing the effects of xenobiotics (Greaves 1982; EPA 1978). However, the use of soil enzymes as a measure of the effects of xenobiotics on soil microorganisms is not without problems. Enzyme activity, like respiration, is not confined to microorganisms; therefore, it is difficult to determine if a measured effect on extracellular enzyme activity correlates with a corresponding effect on microbes (Grossbard 1973b). In addition, there is a lack of unequivocal methods to determine the activities of many soil enzymes.

\subsubsection{Microbial Populations}

There are two fundamental approaches to estimating soil microbial biomass: procedures aimed at enumerating microbial populations, and those aimed at estimating microbial biomass using biochemical approaches (Atlas 1982).

The quantitative enumeration of different microbial populations in soil is difficult. There are no universal methods that can be applied successfully to all microorganisms and all soils. Three methods most often used are 1) the plate count method;2) the most probable number (MPN) method; and 3) the direct cell count method (Atlas 1982). In the plate count method, a diluted soil suspension is inoculated onto a solid medium containing nutrients to support growth. After incubation, the microbial colonies that have formed are counted. The assumption of the technique is that each colony arose from a single inicrobial cell and that each viable microorganism formed a colony. Therefore, the total number of colonies is equated with the original numbers of a microbial 
population. By the use of different carbon sources (e.g., cellulose, chitin), the numbers of microbes having unique biochemical capabilities can be estimated.

The MPN method permits the estimation of population size without an actual count of single cells or colonies. The MPN method is seldom used to enumerate the total number of microorganisms in a soil but rather to enumerate specific groups, such as nitrifiers. The technique employs a statistical approach in which successive dilutions are inade to reach an extinction point (Alexander 1982). Replicates of each dilution are inoculated into (usually) a liquid growth medium, and the pattern of positive and negative scores (i.e., growth) is recorded. A statistical table is then used to determine the most probable number of viable organisms in the original sample. The plate count and MPN methods require that microorganisms grow and divide during the assay. Therefore, these methods have a tendency to underestimate the true size of the different microbial populations in soil, because it is difficult or impossible to duplicate the exact conditions required for the growth of all microorganisms likely to be present in soil.

Direct observation of microbial cells in soils can be achieved by light or electron microscopy, with or without the use of stains (Schmidt and Paul 1982). These methods do not rely on culturing of the selected populations and, therefore, do not require a knowledge of the nutritional and environmental requirements of the microbial populations being studied. A limitation of the direct count method for estimating microbial populations in soils is that it is usually not possible to differentiate living microorganisms from dead. Hence, the method usually overestimates the viable population. Further, populations of individual species cannot usually be enumerated by direct observation.

\subsubsection{Rhizosphere Populations}

Because of their presumed role in increasing the availability and uptake of nutrients by plants, an understanding of the effects of xenobiotics on those microorganisms associated with plant roots is important (Leach 1984). Xenobiotics, particularly pesticides, are often present near the root. Chemicals not directly toxic to microorganisms may indirectly affect rhizosphere microbial populations by changing 
the physiology of the plant and, subsequently, root exudation patterns (Greaves 1982; Trappe et al. 1984).

Techniques for studying rhizosphere microbial populations are not as numerous as those for microorganisms living in soil away from roots. Rhizobia are most frequently enumerated by a MPN method that depends on the ability of the rhizobial cell to cause nodule formation on the roots of a legume host (Weaver and Frederick 1982). Mycorrhizal biomass is often estimated from the density of spores of a specific fungal species in soil (Black and Tinker 1979), stepwise dilution followed by infection of bait plants (Smith and Bowen 1979), and microscopic examination of root segments for mycorrhizal colonization and infection (Hadley and Williamson 1972; Black and Tinker 1979; Powell 1982).

\subsection{ASSESSING THE EFFICACY OF TEST METHODS}

The methods mentioned above, as well as others, have been evaluated by various research groups using a variety of criteria (EPA 1981; Greaves 1982; Domsch et al. 1983). The criteria most often used to accept or reject a method to determine the effects of xenobiotics on microorganisms include:

\section{1. reproduciblity \\ 2. sensitivity \\ 3. standardization (i.e., its potential for interlaboratory transfer) \\ 4. cost \\ 5. time required to perform test \\ 6. level of training required to perform test.}

As can be seen in Table 7.1, no one method has all the desirable attributes necessary such that the results of the test can be accepted unequivocally. However, certain methods have a better overall rating than others. Microbially mediated chemical reactions involved in the mitrogen and carbon cycles appear to be the most sensitive to xenobiotic effects. Because they are sensitive and because they represent processes that determine 
the availability of nutrients, these reactions are good indicators with which to assess the response of soil microorganisms to xenobiotics (Barkay et al. 1986).

Although no international agreement on methods for measuring the effects of xenobiotics on soil microorganisms has been achieved, a number of laboratories have developed systems that offer a reasonable approach to the question. The terrestrial soil-core microcosm (Figure 7.1) is just one such system. Another system, developed by researchers at the Jealott's Hill Research Station in Berkshire, UK (Anderson 1973), appears promising because of its multiplicity of tests and its use of in situ methods. The different methods employed in these two test systems include:

1. respiration (both $\mathrm{CO}_{2}$ evolution and $\mathrm{O}_{2}$ consumption)

2. ${ }^{14} \mathrm{C}$-mineralization studies using plant residues, fresh leaves, sucrose, starch, protein, amino acids, urea lipids, and phenol (expensive and time-consuming)

3. hydrolysis of pectin, DNA, and chitin

4. nitrification

5. activity of phosphatase, peroxidase, and dehydrogenase

6. population densities of Azotobacter sp.

7. population density for bacteria, fungi, and actinomycetes by standard plate count techniques

8. direct counts using UV microscopy

9. ATP assay using the luciferin-luciferase technique. 
Table 7.1. Evaluation of Major Test Systems for Measuring the Effects of Xenobiotics on Soil Microorganisms

\begin{tabular}{|c|c|c|c|c|c|c|}
\hline $\begin{array}{l}\text { Test } \\
\text { Criteria }\end{array}$ & 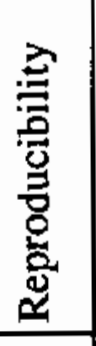 & 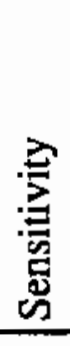 & 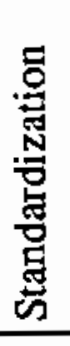 & $\ddot{g}$ & 总 & 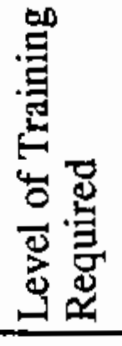 \\
\hline Respiration & $2 *$ & 3 & 1 & 2 & 3 & 2 \\
\hline $\begin{array}{l}\text { Carbon } \\
\text { mineralization }\end{array}$ & 4 & 3 & 3 & 1 & 3 & 1 \\
\hline $\begin{array}{l}\text { Nitrogen } \\
\text { mineralization }\end{array}$ & 3 & 3 & 3 & 2 & 2 & 3 \\
\hline Nitrification & 4 & 4 & 2 & 2 & 1 & 3 \\
\hline $\begin{array}{l}\text { Nitrogen } \\
\text { fixation }\end{array}$ & 4 & 3 & 3 & 2 & 2 & 2 \\
\hline $\begin{array}{l}\text { Phosphorus } \\
\text { transformation }\end{array}$ & 1 & 1 & 2 & 2 & 3 & 2 \\
\hline $\begin{array}{l}\text { Sulfur } \\
\text { transformation }\end{array}$ & 1 & 0 & 2 & 2 & 3 & 2 \\
\hline $\begin{array}{l}\text { Enzymatic } \\
\text { activities }\end{array}$ & 1 & 0 & 2 & 2 & 3 & 2 \\
\hline $\begin{array}{l}\text { Microbial } \\
\text { populations }\end{array}$ & 1 & 1 & 1 & 1 & 2 & 1 \\
\hline
\end{tabular}

* Higher numbers indicate an advantage and lower numbers indicate disadvantage.

Data adapted from EPA (1981); Greaves (1982); Domsch et al. (1983). 
Although these test systems were designed for measuring the effects of pesticides on microbial ecosystems, it seems reasonable that they could be adapted to other, nonpesticidal, xenobiotic compounds. These test systems and others (see Bitton and Dutka 1986) illustrate the need to use several different methodologies to evaluate the toxicity of xenobiotics to soil microorganisms. If the results are integrated in a monitoring scheme, it is highly probable that valid data could be generated that will aid in the assessment of the effects of xenobiotic chemicals.

The results obtained on the effects of a particular xenobiotic on particular microbial processes often depend on the physicochemical properties of the soil used during the test, illustrating again the importance of abiotic factors on microbial effects. Inasmuch as little is known about the influence of most xenobiotic compounds, it is difficult to make meaningful predictions about the effects of xenobiotic compounds in soils different from the one in which the original tests were performed. To remedy this shortcoming, models that adequately predict the abiotic behavior of a compound in any particular soil and sound scientific hypotheses about the subsequent microbiological impact of a compound should be developed.

In addition to developing ecotoxicity systems that meet the six criteria listed in the beginning of this subsection, suitable methods are needed for quantifying the data generated from these tests so that these data can be used easily by the regulatory agencies responsible for formulating criteria for tolerable levels of xenobiotics in the environment (Babich and Stotzky 1985a). The "ecological dose" (EcD) concept, developed by Babicl and Stotzky (see Babich et al. 1981, 1983; Babich and Stotzky 1983, 1985a) and defined as the dose of a toxicant that decreases a specific inicrobe-mediated process by some percentage, represents one method for quantifying the effects of xenobiotics on microbe-mediated processes. This method has been used successfully to quantify the effects of some heavy metals on selected microbe-mediated processes (e.g., glucose mineralization, respiration, nitrification) (Babich et al. 1983), and it appears reasonable that the concept could be modified to quantify the results of toxicity tests that measure the effects of other xenobiotics on microbe-mediated processes. 


\subsection{CONCLUSIONS AND RECOMMENDATIONS}

The intensive use of chemicals in agriculture and the generation of large quantities of chemical wastes from industry has aroused public concern as to how these compounds might affect man and the environment. Because soil is the main sink and repository for many of these chemicals and thus has a major role in determining their ultimate fate, it is critical that the capability to forecast the potential impacts of xenobiotics on soil microorganisms be developed as soon as possible. Once released, the distribution of a xenobiotic between environmental compartments depends on the chemodynamic properties of the compound and on the physicochemical properties of the soil, and it occurs across soil-water and soil-air interfaces and across biological membranes. Abiotic and biotic processes can transform the chemical compound. Ideally, the conversion of the xenobiotic is to carbon dioxide, water, and mineral elements, or at least to some harmless substance. However, intermediate transformation products can be formed that become toxic pollutants in their own right.

As a living environment, the biologic activity of soil is the result of the activities of a host of resident microorganisms, invertebrates, and plants. The microbial components, mainly bacteria, fungi, algae, and protozoa, are important to the fertility of soils through their role in the degradation of plant and animal matter and in the cycling of the organic and inorganic nutrients contained in soil. Among the more important processes mediated by soil microorganisms are the transformation of carbon, nitrogen, phosphorus, and sulfur. Anything that disrupts the activity of the microorganisms could be expected to affect the nutritional quality of soils and would, therefore, have serious ecological consequences. Because of this, it is important to understand the effects of xenobiotic compounds on soil microorganisms and their activities.

In assessing the effects of xenobiotic compounds on soil microorganisms, it is necessary to decide which microbial processes or properties should be evaluated. The most commonly used criteria are those that measure gross or overall activities, such as 
respiration or nitrogen mineralization, sometimes accompanied by total counts of microbial density. However, these parameters lack specificity. Another approach is monitoring changes in physiological activities, such as nitrification, nitrogen fixation, denitrification, decomposition of individual fractions of organic matter, and the metabolism of phosphorus and sulfur.

When exposed to xenobiotic compounds, various segments of the soil microbial community are affected to different extents. The degree to which a xenobiotic affects microbial activities is largely dependent on the chemical, its dosage and method of application, and the particular physicochemical characteristics of the soil, such as soil type, temperature, water content, and $\mathrm{pH}$. Soil physicochemical factors are particularly important and probably account for many of the variations in effects seen with the same compound. A correlation between a compound class and its effects on soil microorganisms is not possible at this time. However, a few generalizations have emerged. Broad-range biocidal compounds, such as soil fungicides, appear to affect all microbial processes, at least temporarily. This is also observed with most heavy metals. Compounds such as herbicides and insecticides are less active against microbial activity and, under certain conditions, may stimulate their activity.

Although all soil microbial processes can be affected to a limited extent by any particular xenobiotic compound, some processes appear more sensitive to xenobiotics than others. For example, nitrification appears to be highly sensitive to xenobiotics, whereas nitrogen mineralization is somewhat insensitive. These results reflect the differences in the microorganisms that mediate these processes. Nitrification is conducted by a select group of chemoautotrophic bacteria, whereas nitrogen mineralization is conducted by a large and diverse group of heterotrophic microorganisms.

The present state of knowledge of the cellular and biochemical effects of xenobiotics is insufficient to delineate their mode of action. However, available data suggest that xenobiotics may interfere with photosynthesis, oxidative metabolism, and the synthesis of cellular constituents. In addition, certain compounds, such as chlorinated aromatics and 
heavy metals, have been shown to alter cellular membrane composition, thereby changing cell membrane permeability and cellular physiology.

Numerous methods exist for measuring different microbial processes, microbial populations, and soil enzymes, and most of these methods can be applied to assessing the effects of xenobiotics. The most pressing issue appears to be deciding which of the available methods are the most valid for investigating xenobiotic effects and how they can be applied for the best results. Additional studies are needed to identify and select the microbially mediated ecological processes that can best be used to generate meaningful data of the short- and long-term effects of xenobiotics before selection and standardization of techniques can be accomplished.

In the interim, however, it is recommended that agencies responsible for monitoring xenobiotic effects use a suite of test methods rather than only one or two. To use time and funds efficiently, these testing programs should have a multitiered design, in which the methods used would increase in complexity as warranted by the potential hazard of the compound. For example, simple, less expensive tests, such as respiration studies, can be used initially to monitor the effect of a xenobiotic compound on soil microorganisms. If the results indicate a strong microbe-xenobiotic interaction, then additional, more complex tests, such as the terrestrial soil-core microcosm test protocol, may be indicated.

Although the answer to the question, "Do xenobiotic compounds impact soil microorganisms?" is yes, the attention that has been given to the effects of xenobiotics on soil microorganisms does not yet provide a systematic approach by which environmental risk assessments can be performed for all classes of xenobiotics with any degree of accuracy or confidence.

Agricultural chemicals do not appear to have any long-term harmful effects on soil microbial activity when applied at recommended field levels (Greaves et al. 1976; Smith 1982; Wainwright 1978; Grossbard 1976; Parr 1974). However, when applied at higher levels than recommended, these compounds do appear to have an adverse short-term 
effect, particularly on nitrogen and carbon transformations (Wainwright 1978; Barkay et al. 1986; Grossbard 1976). Furthermore, contradictory results are often observed for the same chemical applied at the same levels (Barkay et al. 1986). Although these contradictory results are often explained on the basis of differences in laboratory procedures or soil types, no generally accepted explanations exist.

These contradictory results illustrate the basic problems that must be resolved before an adequate predictive environmental risk assessment capability can be developed for the effects of xenobiotics on microorganisms in soil. First, a standardized system (i.e., test method and defined test protocol) for evaluating the effects of xenobiotics on soil microorganisms must be established. Such a system would give both industry and regulatory agencies the capability to assess adequately the effects of different compounds on microbial processes. Second, information correlating the effects of certain groups of compounds, e.g., the chlorinated or $\mathrm{N}$-containing aromatics, on the growth and activities of soil microorganisms and the specific physiological effects of the different compound classes must be obtained before an adequate predictive environmental risk assessment capability can be developed. To resolve these two problems, the following research is recommended:

A. The development of a comprehensive system for evaluating the effects of xenobiotics on soil microbial activity be established. Establishing such a system should involve:

1. Identification and selection of the microbially mediated processes that can best be used to generate quantitative data concerning the long- and short-term effects of xenobiotics.

2. Review and selection of methods currently used to measure the selected processes. In reviewing current ecotoxicity test systems, the following criteria are recommended: 1) the results should be capable of being reproduced in other laboratories; 2) the methods should be amenable to standardization techniques; 3) the tests should be sensitive to low levels of xenobiotics that are often found in soil; 4) the test systems should be as 
realistic as possible with respect to both the environmental conditions, the environmental dose, and the form of the xenobiotic; and 5) the methods should be both economical and uncomplicated without losing reliability.

3) Further development of methods to quantify and evaluate data of the short- and long-term effects of xenobiotics on microorganisms in soil [e.g., the EcD concept (Babich et al. 1981, 1983; Babich and Stotzky $1983,1985 a)$. Such quantification of the effects of xenobiotics on microbe-mediated processes could be utilized by the regulatory agencies to formulate criteria for acceptable levels of xenobiotics in soil.

B. A systematic evaluation of the various compound classes is needed to establish whether a correlation exists between compound structure and inhibitory effects on microbial processes. At present, no unequivocal correlations between compound structure and effects have been established. In addition, there is a paucity of information conceming the effects of nonagricultural xenobiotic organic compounds on soil microorganisms. Although this task might be monumental in both effort and cost, it would provide the basic scientific information needed to predict, based on the chemical properties of a compound, its ecotoxicological behavior with respect to microorganisms in soil. Such an evaluation should include:

1. Establishment of a comprehensive data base of the known effects of xenobiotics on soil microbial activity to determine if a statistical correlation between compound structure and effects is currently available.

2. Performance of laboratory tests (using selected microbially mediated processes) on compound classes that have not been previously evaluated. 


\subsection{REFERENCES}

Agrios, G. N. 1978. Plant Patholegy. 2nd edition. Academic Press, New York.

Alexander, M. 1977. Introduction to Soil Microbiology. 2nd edition. Wiley, New York.

Alexander, M. 1981. Biodegradation of chemicals of environmental concern. Science 211:132-138.

Alexander, M. 1982. Most probable number method for microbial populations. In: Methods of Soil Analysis. Part 2: Chemical and Microbiological Properties, 2nd edition, ed. A.L. Page, R. H. Miller, and D.R. Keeney, pp. 815-820. American Society of Agronomy, Madison, WI.

Anderson, J. P. E. 1982. Soil respiration. In: Methods of Soil Analysis, Part 2: Chemical and Microbiological Properties, 2nd edition, eds. A. L. Page, R. H. Miller, and D. R. Keeney, pp. 831-871. American Society of Agronomy, Madison, WI.

Anderson, J. R. 1973. A system for evaluating effects of pesticides on soil microbial activity. Bull, Ecol, Res. Comm. (Stockholm) 17:473-474.

Anderson, J. R. and E. A. Drew. 1976. Effects of pure paraquat dichloride, 'Gramoxone W', and formulation additive on soil microbiological activities. 2. Effects on respiration, organic matter mineralization, and nitrification in laboratory-treated soil. Zentrabl.Bakteriol. Abt. II 131:136-147.

Atlas, R. M. 1982. Enumeration and estimation of microbial biomass. In: Experimental Microbial Ecology, eds. R. G. Burns and J. H. Slater, pp. 84-102. Blackwell Scientific Publications, London.

Atlas, R. M. and R. Bartha. 1987. Microbial Ecology: Fundamentals and Applications. Benjamin Cummings, Menlo Park, CA.

Audus, L. J. 1970. The action of herbicides and pesticides on the soil microflora. Meded. Fac. Landbouwwet. Rijksuniv. Gent. 35: 465-492.

Ausmus, B. S., S. S. Kimbrough, D. R. Jackson, and S. Lindberg. 1979. The behavior of hexachlorobenzene in pine forest microcosms: transport and effects on soil processes. Environ. Pollut. 20:103-111.

Babich, H. and G. Stotzky. 1977. Reductions in the toxicity of cadmium to microorganisms by clay minerals. Appl. Environ. Microbiol, 33:696-705. 
Babich, H. and G. Stotzky. 1978. Effects of cadmium on the biota: influence of environmental factors. Adv. Appl. Microbiol, 23:55-117.

Babich, H. and G. Stotzky. 1979. Abiotic factors affecting the toxicity of lead to fungi. Appl. Environ. Microbiol, 38:506-513.

Babich, H. and G. Stotzky. 1982. Gaseous and heavy metal air pollutants. In: Experimental Microbial Ecology, eds. R. G. Burns and J. H. Slater, pp. 631-670. Blackwell Scientific Publications, London.

Babich, H. and G. Stotzky. 1983. Developing standards for environmental toxicants: The need to consider abiotic environmental factors and microbe-mediated ecologic processes. Environ. Health Perspect. 49:247-260.

Babich, H. and G. Stotzky. 1985a. Heavy metal toxicity to microbe-mediated ecological processes: a review and potential application to regulatory policies. Environ. Res. 36:111-137.

Babich, H. and G. Stotzky. 1985b. Microbial assays for determining the influence of physicochemical environmental factors on the toxicity of organics: phenol. Arch. Environ. Contam. Toxicol, 14:409-415.

Babich, H., R. J. F. Bewley, and G. Stotzky. 1983. Application of the "ecological dose" concept to the impact of heavy metals on some microbe-mediated ecological processes in soil. Arch. Environ. Contam. Toxicol, 12:421-428.

Babich, H., D. L. Davis, and J. Trauberman. 1981. Environmental quality criteria: some considerations. Environ. Manage 5:191-205.

Barkay, T., D. F. Shearer, and B. H. Olson. 1986. Toxicity testing in soil using microorganisms. In: Texicity Testing Using Microorganisms, Vol. II, eds. B. J. Dutka and G. Bitton, pp. 133-155. CRC Press, Boca Raton, FL.

Bartha, R. and D. Pramer. 1965. Features of a flask method for measuring persistence and biological effects of pesticides in soil. Soil Sci, 100:68-70.

Bartha, R., R. P. Lanzillota, and D. Pramer. 1967. Stability and effects of some pesticides in soil. Appl. Microbiol. 15:67-75.

Baver, L. D., W. H. Gardner, and W. R. Gardner. 1972. Soil Physics. Wiley, New York.

Beste, C. E. 1983. Herbicide Handbook. Weed Science Society of America, Champaign, IL. 
Bewley, R. J. F. and G. Stotzky. 1983. Effects of cadmium and zinc on microbial activity in soil; influence of clay minerals. Part II: Metals added simultaneously. Sci. Total Environ 31:57-69.

Beyers, R. J. 1964. The microcosm approach to ecosystem biology. Am Biol, Teacher 26(7):491-498.

Bitton, G. and B. J. Dutka. 1986. Introduction and review of microbial and biochemical toxicity screening procedures. In: Toxicity Testing Using Microorganisms. Vol. II, eds. B. J. Dutka and G. Bitton, pp. 1-8. CRC Press, Boca Raton, FL.

Black, R. L. B. and P. B. Tinker. 1979. The development of endomycornhizal root systems. II. Effect of agronomic factors and soil conditions on the development of vesicular-arbuscular mycorrhizal infection in barley and on the endophyte spore density. New Phytologist 83:401-413.

Bollag, J.-M. and N. M. Henninger. 1976. Influence of pesticides on denitrification in soil and with an isolated bacterium. J. Environ. Oual. 5:15-18.

Bollag, J.-M. and C. L. Nash. 1974. Effect of chemical structure of phenylurea and anilines on the denitrification process. Bull, Environ. Contam. Toxicol. 12:241-248.

Bonmati, M., M. Pujola, J. Sana, M. Soliva, M. T. Felipo, M. Garau, B. Ceccanti, and P. Nannipieri. 1985. Chemical properties, populations of nitrite oxidizers, urease and phosphatase activities in sewage sludge-amended soils. Plant Soil 84:79-91.

Boyd, S. A. and D. R. Shelton. 1984. Anaerobic biodegradation of chlorophenols in fresh and acclimated sludge. Appl. Environ. Microbiol, 47:272-277.

Burns, R. G. 1979. Interaction of microorganisms, their substrates and their products with soil surfaces. In: Adhesion of Microorganisms to Surfaces, eds. D. C. Ellwood, J. Melling, and P. Rutter, pp. 107-138. Academic Press, London.

Burns, R. G. 1983. Extracellular enzyme-substrate interactions in soil. In: Microbes in Their Natural Environment, eds. J. H. Slater, R. Whittenbury and J. W. T. Wimpenny, pp. 249-298. Cambridge University Press, London.

Burns, R. G. 1986. Interaction of enzymes with soil mineral and organic colloids. In: Interactions of Soil Minerals with Natural Organics and Microbes, eds. P. M. Huang and M. Schnitzer, pp. 429-451. Soil Science Society of America, Madison, WI. 
Capone, D. G., D. D. Reese, and D. P. Kiene. 1983. Effects of metals on methanogenesis, sulfate reduction, carbon dioxide evolution, and microbial biomass in an anoxic salt march sediment. Appl. Environ. Microbiol. 45:1586-1591.

Caims, J., A. L. Buikema, A. G. Heath, and B. C. Parker. 1978. Effects of temperature on aquatic organism sensitivity to selected chemicals. Virginia Water Resources Research Center, Bulletin 106. Virginia Polytechnic Institute, Blacksburg, Virginia.

Chang, F. H. and F. E. Broadbent. 1982. Influence of trace metals on some soil nitrogen transformations. J. Environ, Oual 11:1-4.

Clegg, T. J. and J. L. Koevening. 1974. The effect of four chlorinated hydrocarbon pesticides and one organophosphate pesticide on ATP levels in three species of photosynthetic freshwater algae. Bot. Gaz, 135:368-372.

Cole, L. K., R. L. Metcalf, and J. R. Sandborn. 1976. Environmental fate of insecticides in terrestrial model ecosystems. Int. J. Environ, Studies 10:7-14.

Cole, M. A. 1976. Effect of long-tern atrazine application on soil microbial activity. Weed Sci, 24:473-476.

Coleman, R. 1966. The importance of sulfur as a plant nutrient in world crop production. Soil Sci 101:230-239.

Corke, C. T. and F. R. Thompson. 1970. Effects of some phenylamide herbicides and their degradation products on soil nitrification. Can, J. Microbiol, 16:567-571.

Cullimore, D. R. and L. Ball. 1978. New monitoring system for proteolysis in soil as influenced by selected herbicidal applications. Appl, Environ, Microbiol, 36:959-961.

Debosz, K., H. Babich, and G. Stotzky. 1985 . Toxicity of lead to soil respiration: mediation by clay minerals, humic acids, and compost. Bull. Environ. Contam. Toxicol, 35:517-524.

Dixon; J. B. and S. B. Weed. 1977. Minerals in Soil Environments. Soil Science Society of America, Madison, WI.

Doelman, P. and L. Haanstra. 1984. Short-term and long-term effects of cadmium, chromium, copper, nickel, lead, and zinc on soil microbial respiration in relation to abiotic soil factors. Plant Soil 79: 317-327.

Doetsch, R. N. and T. M. Cook. 1974. Introduction to Bacteria and Their Ecobiology. University Park Press, London. 
Domsch, K. H., G. Jagnow, and T. H. Anderson. 1983. An ecological concept for the assessment of side effects of agrochemicals on soil microorganisms. Res. Rev. 86:65-105.

Dubey, H. D. 1969. Effect of Picloram, Diuron, Ametryne, and Prometryne on nitrification in some tropical soils. Soil Sci. Soc. Am. J. 33:893-896.

Dubey, H. D. and R. L. Rodriguez. 1970. Effect of Dyrene and Maneb on nitrification and ammonification, and their degradation in tropical soils. Soil Sci. Soc. Am.J. 34:435-439.

EPA. 1978. Environmental Protection Agency, Registration of pesticides in the United States, proposed guidelines. Federal Register 43 (132), Part II: 29696-29741.

EPA. 1981. Ecotoxicological Test Systems: Proceeding of a Series of Workshops. EPA-560/6-81-004.

Farmer, V. C. 1978. Water on particle surfaces. In: The Chemistry of Soil Constituents, eds. D. J. Greenland and M. H. B. Hayes, pp. 405-408, Marcel Dekker, New York.

Farrah, H. and W. F. Pickering. 1978a. Influence of clay-solute interactions on aqueous metal ion levels. Water Air Soil Pollut. 8:189-197.

Farrah, H. and W. F. Pickering. 1978b. The effects of $\mathrm{pH}$ and ligands on the sorption of heavy metal ions by cellulose. Austr. J. Chem. 31:1510-1509.

Frankenberger, W. T., F. R. Trœeh, and L. C. Dumenil. 1979. Bacterial effects on hydraulic conductivity of soils. Soil Sci. Soc. Am. J 43:333-338.

Gaur, A. C. and K. C. Misra. 1977. Effect of Simazine, Lindane, and Ceresan on soil respiration and nitrification rates. Plant Soil 46: 5-15.

Gerhardson, B. and M. Clarholm. 1986. Microbial communities and plant roots. In: Microbial Communities in Soil, eds. V. Jensen, A. Kjoller, and L. H. Sorensen, pp. 19-34. Elsevier, New York.

Ghiorse, W. C. 1984. Biology of iron- and manganese-depositing bacteria. Ann. Rev, Microbiol. 38:515-550.

Giashuddin, M. and A. H. Cornfield. 1979. Effects of adding nickel (as oxide) to soil on nitrogen and carbon mineralization at different $\mathrm{pH}$ levels. Environ. Pollut. 19:67-70.

Gibson, D. T. 1984. Microbial Degradation of Organic Compounds. Marcel Dekker, New York. 
Giesy, J. P. Jr., ed. 1980. Microcosms in Ecological Research. CONF. 7891101. Technical Information Center, U.S. Department of Energy, Washington, D.C.

Gile, J. D., J. W. Gillett, and J. C. Collins. 1979. The Soil-Core Microcosm-Potential Screening Tool. Ecol. Res. Ser., EPA 600/3-78-0010. U.S. Environmental Protection Agency, Corvallis, OR.

Gillett, J. W. and J. D. Gile. 1976. Pesticide fate in terrestrial laboratory ecosystem. Int. J, Environ. Studies 10:15-22.

Gillett, J. W. and J. M. Witt, eds. 1979. Terrestrial Microcosms. Proceedings of the workshop on terrestrial microcosms. NSF/RA 79-0027. National Sciences Foundation, Washington, D.C.

Granat, L., R. O. Hallberg, and H. Rodhe. 1976. The global sulfur cycle. In: Nitrogen. Phosphorus and Sulfur-Global Cycles, eds. B. H. Svensson and R. Soderlund, SCOPE Report 7. Ecol, Bull, (Stockholm) 22: 23-73.

Greaves, M. P. 1982. Effect of pesticides on soil microorganisms. In: Experimental Microbial Ecology, eds. R.G. Burns and J.H. Slater, pp. 613-630. Blackwell Scientific Publications, London.

Greaves, M. P., H. A. Davies, J. A. P. Marsh, and G. I. Wingfield. 1976. Herbicides and soil microorganisms. CRC Crit. Rev Microbiol. 5:1-38.

Greaves, M. P., N. J. Poole, K. H. Domsch, G. Jagnow, and W. Verstraete. 1980. Recommended Tests for Assessing the Side-Effects of Pesticides on the Soil Microflora. Technical Report, Agricultural Research Council Weed Research Organization, Number 59.

Grossbard, E. 1973a. Rapid techniques for the assessment of the effects of herbicides on soil microorganisms and cellulolytic activity. Bull. Ecol. Res. Comm. (Stockholm) 17:473-474.

Grossbard, E. 1973b. Problems of assessing the effects of pollutants on microbial activity. Bull. Ecol, Res. Comm. (Stockholm) 17:457-463.

Grossbard, E. 1976. Effects on the soil microflora. In: Herbicides: Physiology Biochemistry, and Ecology, ed. L. J. Audus, pp. 99-147. Academic Press, New York.

Grossbard, E. and H. A. Davies. 1976. Specific microbial response to herbicides. Weed Res. 16:163-169.

Hadley, G. and B. Williamson. 1972. Features of mycorrhizal infection in some Malayan orchids. New Phytologist 71:445-455. 
Hartley, D. and H. Kidd. 1983. The Agrochemical Handbook. The Royal Society of Chemistry. Unwin Brothers Ltd., Old Woking, Surrey, England.

Hicks, G. F. and T. R. Comer. 1973. Location and consequences of 1,1,1-trichloro-2,2-bis( $p$-chlorophenyl) ethane uptake by Bacillus megaterium. Appl. Microbiol. 25: 381-385.

Hutzinger, O. and W. Veerkamp. 1981. Xenobiotic chemicals with pollution potential. In: Microbial Degradation of Xenobiotics and Recalcitrant Compounds, eds. T. Leisinger, R. Hutter, A. M. Cook, and J. Nuesch, pp. 3-45. Academic Press, London.

Jenkinson, D. S. and D. S. Powlson. 1976. The effects of biocidal treatments on metabolism in soil. Part V: A method for measuring soil biomass. Soil Biol. Biochem. 8: 209-213.

Juneja, S. and R. C. Dogra. 1978. Effect of aldrin on growth and oxidative metabolism of rhizobia. J. Appl. Bacteriol 49:107-115.

Juma; N. G. and M. A. Tabatabi. 1977. Effects of trace elements on phosphatase activity in soils. Soil Sci, Soc. Am. J, 41:343-346.

Keswick, B. H. 1984. Sources of groundwater pollution. In: Groundwater Pollution Microbiology, eds. G. Bitton and C. P. Gerba, pp. 39-64. Wiley, New York.

Khan, D. H. and B. Frankland. 1984. Cellulytic activity and root biomass production in some metal-contaminated soils. Environ, Pollut. 33: 63-74.

Knowles, R. 1982. Free-living nitrogen-fixing bacteria. In: Methods of Soil Analysis, Part 2: Chemical and Microbiological Properties, 2nd edition, eds. A. L. Page, R.H. Miller, and D.R. Keeney, pp. 1071-1092. American Society of Agronomy, Madison, WI.

Kobayashi, H. and B. E. Rittmann. 1982. Microbial removal of hazardous organic compounds. Environ. Sci. Technol, 16:170A-183A.

Ladd, J. N. 1978. Origin and range of enzymes in soil. In: Soil Enzymes, ed. R. G. Burns, pp. 51-96. Academic Press, London.

Lal, R. and D. M. Saxena. 1979. Cytological and biochemical effects of pesticides on microorganisms. Res. Rev, 73:49-86.

Lal, R. and D. M. Saxena. 1980. Effect of DDT on cell population growth of Tetrahymena pyriformis. Arch. Protistenkd. 122:382-386. 
Lal, R. and D. M. Saxena. 1982. Accumulation, metabolism, and effects of organochlorine insecticides on microorganisms. Microbiol, Rev 46: 95-127.

Leach, F. R. 1984. Biochemical indicators of groundwater pollution. In: Groundwater Pollution Microbiology, eds. G. Bitton and C.P. Gerba, pp. 303-351. Wiley, New York.

Liang, C. N. and M. A. Tabatabai. 1978. Effects of trace elements on nitrification in soils. J. Environ, Qual. 7:291-293.

Litchfield, C. D. and R. P. Huben. 1973. Effect of selected pollutants on the specific growth rate and extracellular enzyme synthesis of Aeromonas proteolytica. Bull. Ecol.Res. Comm. (Stockholm) 17:464-466.

Low, P. F. 1961. Physical chemistry of clay-water interactions. Adv, Agron. $13: 269-327$.

Low, P. F. 1979. Nature and properties of water in montmorillonite-water systems. Soil Sci, Soc. Am. J. 43:651-658.

Lynch, J. M. 1983. Soil Biotechnology: Microbiological Factors in Crop Productivity. Blackwell Scientific Publications, London.

Martin, M. H., E. M. Duncan, and P. J. Coughtrey. 1982. The distribution of heavy metals in a contaminated woodland ecosystem. Environ. Pollut. Sci. B 3:147-157.

Metcalf, R. L. 1977. Model ecosystem approach to insecticide degradation - a critique. Ann. Rev. Entomol, 22:241-262.

Ogram, A. V., R. E. Jessup, L. T. Ou, and P. S. C. Rao. 1985. Effects of sorption on biological degradation rates of (2,4-dichlorophenoxy) acetic acid in soils. Appl. Environ, Microbiol, 49:582-587.

Papendick, R. I. and G. S. Campbell. 1980. Theory and measurement of water potential. In: Water Potential Relations in Soil Microbiology, ed. D. M. Kral, pp.1-22. Soil Science Society of America, Madison, WI.

Parasher, C. D., M. Ozel, and F. Geike. 1978. Effect of hexachlorobenzene and acetone on algal growth, physiology and ultrastructure. Chem. Biol, Interact. 20:89-95.

Parr, J. F. 1974. Effects of pesticides on microorganisms in soil and water. In: Pesticides in Soil and Water, ed. W.D. Guenzi, pp. 315-340. Soil Science Society of America, Madison, WI.

Patten, B. C. and M. Witkamp. 1967. Systems analysis of ${ }^{134} \mathrm{Cs}$ kinetics in terrestrial microcosms. Ecology 48:813-824. 
Payne, W. J. 1973. The use of gas chromatography for studies of denitrification in ecosystems. In: Modern Methods in the Study of Microbial Ecology. Ecological Bulletin 17, ed. T. Rosswall, pp. 262-268. Swedish Natural Science Research Council, Stockholm.

Powell, C. L. 1982. Mycorrhizae. In: Experimental Microbial Ecology, eds. R. G. Bums and J. H. Slater, pp. 447-471. Blackwell Scientific Publications, London.

Reineke, W. 1984. Microbial degradation of halogenated aromatic compounds. In: Microbial Degradation of Organic Compounds, ed. D.T. Gibson, pp. 319-360. Marcel Dekker, New York.

Rosas, S. B., M. D. C. Secco, and N. E. Ghittoni. 1980. Effects of pesticides on the fatty acid and phospholipid composition of Escherichia coli. Appl. Environ. Microbiol, 40:231-234.

Roslycky, E. B. 1985. Paraquat-induced changes in selected rhizobia and agrobacteria. Can. J. Soil Sci, 65:667-675.

Rother, J. A., J. W. Millbank, and I. Thomton. 1982. Seasonal fluctuations in nitrogen fixation (acetylene reduction) by free-living hacteria in soils contaminated with cadmium, lead, and zinc. J. Soil Sci, 33:101-113.

Rovira, A. D. 1976. Studies on soil fumigation. I. Effects on ammonium nitrate and phosphate in soil and on the growth, nutrition, and yield of wheat. Soil Biol. Biochem. 8:241-247.

Russell, E. W. 1973. Soil Conditions and Plant Growth 10th edition. Longman, London.

Saive, R. 1974. Action of pesticides on soil microorganisms. Ann. Gembloux $80: 55-77$

Sanders, F. E. 1986. The role of mycorrhiza in plant nutrient uptake fron soil. In: Microbial Communities in Soil, eds. V. Jensen, A. Kjoller, and L. H. Sorensen, pp. 61-72. Elsevier, New York.

Schippers, B., P. A. H. M. Bakker, A. W. Bakker, P. J. Weisbeek, and B. Lugtenberg. 1986. Plant growth-inhibiting and stimulating rhizosphere microorganisms. In: Microbial Communities in Soil, eds. V. Jensen, A. Kjoller, and L. H. Sorensen, pp. 35-48. Elsevier, New York.

Schlegel, H. G. and H. W. Jannasch. 1981. Prokaryotes and their habitats. In: The Prokaryotes, eds. M.P. Starr, H. Stolp, H. G. Truper, A. Balows, and H. G. Schlegel, pp. 43-82. Springer-Verlag, New York. 
Schmidt, E. L. and E. A. Paul. 1982. Microscopic methods for soil microorganisms. In: Method of Soil Analysis, Part 2: Chemical and Microbiological Properties, 2nd edition, eds. A. L. Page, R.H. Miller, and D.R. Keeney, pp. 803-814. American Society of Agronomy, Madison, WI.

Schwab, S. M., E. L. V. Johnson, and J. A. Menge. 1982. Influence of Simazine on formation of vesicular-arbuscular mycorhizae in Chenopodium quinona Willd. Plant Soil 64:238-287.

Simon-Sylvestre, G. and J. C. Fournier. 1979. Effects of pesticides on the soil microflora. Adv, Agron, 31:1-92.

Smith, A. E. 1982. Herbicides and the soil environment in Canada. Can. J. Soil Sci. $62: 433-460$.

Smith, M. S. and C. S. Weeraratna. 1974. The influence of some biologically active compounds on microbial activity and on availability of plant nutrients in soils. Pest. Sci. 5: 721-729.

Smith, S. E. and G. D. Bowen. 1979. Soil temperature, mycorrhizal infection and nodulation of Medicago trunculata and Trifolium subterraneum. Soil Biol. Biochem. 11:469-473.

Stevenson, F. J. 1985. Humus Chemistry. Wiley, New York.

Stevenson, F. J. and A. Finch. 1986. Chemistry of complexation of metal ions with soil solution organics. In: Interactions of Soil Minerals with Natural Organics and Microbes, eds. P. M. Huang and M. Schnitzer, pp. 29-58. Soil Science Society of America, Madison, WI.

Stotzky, G. 1974. Activity, ecology, and population dynamics of microorganisms in soil. In: Micobial Ecology, eds. A.I. Laskin and H. Lechevalier, pp. 57-135. Chemical Rubber Company, Cleveland, $\mathrm{OH}$.

Stotzky, G. 1986. Influence of soil mineral colloids on metabolic processes, growth, adhesion, and ecology of microbes and viruses. In: Interactions of Soil Minerals with Natural Organics and Microbes, eds. P. M. Huang and M. Schnitzer, pp. 305-428. Soil Science Society of America, Madison, WI.

Stotzky, G. and R. G. Burns. 1982. The soil environment: clay-humus-microbe interactions. In: Experimental Microbial Ecology, eds. R.G. Burns and J.H. Slater, pp. 105-133. Blackwell Scientific Publications, London.

Stotzky, G. and S. Schenck. 1976. Volatile organic compounds and microorganisms. Crit. Rev. Microbiol, 4:333-382. 
Thomton J. and A. D. McLaren. 1975. Enzymatic characterization of soil evidence. J. Forensic Sci. 20:674-692.

Tiedje, J. M. 1982. Denitrification. In: Method of Soil Analysis, Part 2: Chemical and Microbiological Properties. 2nd edition, eds. A. L. Page, R.H. Miller, and D.R. Keeney, pp. 1011-1026. American Society of Agronomy, Madison, WI.

Tinsley, I. J. 1979. Chemical Concepts in Pollutant Behavior. Wiley, New York.

Tolle, D. A., M. F. Arthur, and P. Van Voris. 1983. Microcosm/field comparison of trace element uptake in crops grown in fly ash-amended soil. Sci. Total Environ. 31:243-261.

Tolle, D. A., P. Van Voris, M. F. Arthur, J. P. Morris, and M. Larson. 1981. Evaluation of terrestrial microcosms for predicting ecosystem response to perturbation. Bull. Ecol. Soc, Am, 62:141-142.

Trappe, J. M., R. Molina, and M. Castellano. 1984. Reactions of mycorrhizal fungi and mycorrhiza formation to pesticides. Ann. Rev. Phytopathol, 22:331-359.

Tu, C. M. and W. B. Bollen. 1968. Effect of paraquat on microbial activities in soils. Weed Res. 8:28-31.

Tu, C. M. and J. R. W. Miles. 1976. Interactions between insecticides and soil microbes. Res. Rev 64:5-65.

Tyler, G. 1975. Effect of heavy metal pollution on decomposition and mineralization rates in forest soils. In: Proc. Symp. Int. Conf, on Heavy Metals in the Environment, Toronto, 2: 217-226.

Tyunyayeva, G. N., A. K. Minenko, and L. A. Ponkov. 1974. Effect of trifluralin on the biological properties of soil. Soviet Soil Sci, 6:320-324:

Van Voris, P., D. A. Tolle, M. F. Arthur, J. Chesson, and T. C. Zwick. 1984. Development and Validation of a Terrestrial Microcosms Test System for Assessing Ecological Effects of Utility Wastes. EA-3672. Project 1224-5, Electric Power Research Institute, Palo Alto, CA.

Van Voris, P., D. A. Tolle, and M. F. Arthur. 1985a. The Experimental Terrestrial Soil-Core Microcosm Test Protocol. EPA-600/3-85/047.

Van Voris, P., D.A. Tolle, M. F. Arthur, and J. Chesson. 1985b. Terrestrial microcosms: applications, validation and cost-benefit analysis. In: Multispecies Toxicity Testing, ed. J. Caims, Jr., pp. 117-143. Pergamon Press, New York.

Wainwright, M. 1978. A review of the effects of pesticides on microbial activity in soils. J. Soil Sci. 29: 287-298. 
Wainwright, M. and F. J. Snowden. 1977. Influence of fungicide treatment on $\mathrm{CaCl}_{2}$-extractable phosphorus and phosphate solubilizing microorganisms. Plant Soil 48: 335-345.

Warington, R. 1851. Notice of observations on the adjustment of the relation between animal and vegetation kingdoms. Q. J. Chem. Soc. 3:52-54.

Warington, R. 1857. On the aquarium. Proc. R. Inst, London 2:403-408.

Weaver, R. W. and L. R. Frederick. 1982. Rhizobium. In: Method of Soil Analysis, Part 2: Chemical and Microbiological Properties. 2nd edition, eds. A. L. Page, R.H. Miller, and D.R. Keeney, pp. 1043-1070. American Society of Agronomy, Madison, WI.

Widus, R., P. W. Trudgill, and M. J. Maliszewski. 1971. The effect of technical chlordane on energy metabolism of Bacillus megaterium. I. Gen. Microbiol. 69:15-22.

Wurster, C. F., Jr. 1968. DDT reduces photosynthesis of marine phytoplankton. Science 159: 1474-1475.

Zachara, J. M., L. J. Felice, R. G. Riley, F. L. Harrison, and B. Mallon. 1984. The Selection of Organic Chemicals for Subsurface Transport Research. DOE/ER-0217. National Technical Information Service (NTIS), Springfield, VA. 


\section{DISTRIBUTION}

No. of

Copies

\section{OFFSITE}

20 C. W. Hendricks

U.S. Environmental Protection Agency

Environmental Research Laboratory

Ecotoxicology Branch

200 S.W. 35th Street

Corvallis, Oregon 97333

H. V. Kibby

U.S. Environmental Protection Agency

Environmental Research Laboratory

Ecotoxicology Branch

200 S.W. 35th Street

Corvallis, Oregon 97333

R. J. Seidler

U.S. Environmental Protection Agency

Environmental Research Laboratory

Ecotoxicology Branch

200 S.W. 35th Street

Corvallis, Oregon 97333

10 DOE Technical Information Center
No. of

Copies

ONSITE

DOE Richland Operations Office

J. J. Sutey

21 Pacific Northwest Laboratory

H. Bolton, Jr.

D. W. Dragnich

J. K. Fredrickson

J. M. Hales

P. C. Hays

R. J. Hicks (3)

S. A. Kreml

L. E. Rogers

J. A. Stottlemyre

P. Van Voris

S. G. Weiss

R. E. Wildung

Publishing Coordination (2)

Technical Report Files (5) 


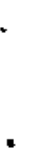

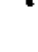

